\title{
Blockchain technology adoption for managing risks in operations and supply chain management: evidence from the UK
}

\author{
Soumyadeb Chowdhury ${ }^{1}$ (D) - Oscar Rodriguez-Espindola ${ }^{2} \cdot$ Prasanta Dey $^{2}$. \\ Pawan Budhwar ${ }^{3}$
}

Accepted: 6 December 2021

(c) The Author(s), under exclusive licence to Springer Science+Business Media, LLC, part of Springer Nature 2022

\begin{abstract}
The impact of blockchain technology (BCT) implementation on the accuracy, reliability, visibility, incorruptibility, and timeliness of supply-chain processes and transactions, makes it attractive to improve the robustness, transparency, accountability and decision-making in risk management. Therefore, the emerging BCT can present an invaluable opportunity for the organisations in need of preparing for and responding to uncertain and complex instances. The adoption of BCT in the operations and supply chain management (OSCM) literature remains scarcely investigated, especially in the context of managing risks in emergency situations such as crises, disasters, and pandemics, which are characterised by volatility, uncertainty, complexity and ambiguity (VUCA) in the business environment. This article will contribute to the OSCM literature by developing a conceptual model that will examine the causal relationships between VUCA business environment, constructs derived from technology acceptance model (TAM), resilience and behavioural intention of the operations managers to adopt BCT for risk management. The model was tested by gathering responses from 116 operations managers in the UK (during COVID-19 pandemic) through structural equation modelling. Findings from the analysis suggest that understanding the benefits of $\mathrm{BCT}$, involvement in resilient organisational practices and user-friendly implementation of the technology will have a significant and positive influence on the intention to adopt BCT for risk management in the OSCM context. Building upon these findings, we have proposed a BCT decision framework to assess the feasibility and suitability of adopting BCT in each context (such as risk management), which will have strategic implications for operations managers and the OSCM community.
\end{abstract}

Keywords Blockchain technology · Risk management · TAM · VUCA environment · Structural equation modelling $\cdot$ Decision framework

Soumyadeb Chowdhury

S.Chowdhury@tbs-education.fr

1 Information, Operations and Management Sciences, Toulouse Business School, 1 Place Alphonse Jourdain, 31068 Toulouse, France

2 Operations and Information Management Department, Aston Business School, Aston University, Aston Triangle B4 7ET, Birmingham, UK

3 Work and Organisation Department, Aston Business School, Aston University, Birmingham, UK 


\section{Introduction}

The challenges experienced by supply chain operations in the current decade along with the effect of the ongoing COVID-19 pandemic have become increasingly more complex. Facing these problems requires strong collaborative, co-ordinated and trust-worthy efforts from and across a broad spectrum of stakeholders in the entire supply-chain. One such area where these efforts are currently being devoted is risk management, which can increase resilience of the operational processes in the supply chain (Manhart et al., 2020; Munir et al., 2020). Risk management is an important dimension in operations and supply chain management (OSCM) and has been extensively studied as well, as reported in the literature (Araz et al., 2020; Jüttner, 2005; Tang, 2006; Wang et al., 2020). The significance of managing risks within the operational processes to prevent supply chain disruptions caused by emergency situations will help to make business organisations resilient, productive and gain competitive advantage, as highlighted in the OSCM literature (Ivanov \& Dolgui, 2020; Xu et al., 2020). In this context, blockchain technology (BCT) has emerged as a promising innovation which cannot only disrupt the operational processes within the supply chain of products and services, but it can facilitate risk management within the complex and interconnected global supply chain ecosystem by enhancing both the information and process resilience (Tönnissen \& Teuteberg, 2020; Esmaeilian et al., 2020; Wamba \& Queiroz, 2020; Gurtu \& Johny, 2019; Kshetri, 2018).

$\mathrm{BCT}$ is based on the peer-peer (P2P) network topology, offering a digital distributed and decentralized ledger that allows security, immutability and sharing of data in real-time among various stakeholders in a supply chain (Akter et al., 2020). BCT adoption and implementation is facilitated in OSCM as a result of trends supporting digital transformation (Akter et al., 2020; Malyavkina et al., 2019), Industry4.0 (Bodkhe et al., 2020), and availability as well as advancement of analytics capability resulting from Intelligent Internet of Things (IIoT) technologies (Singh et al., 2020). The BCT features such as transparency, visibility, disintermediation, decentralization and immutability in business operations and transactions will result in more flexible and efficient processes and communication mechanisms (Hastig \& Sodhi, 2020). This will be facilitated by information creation, sharing, consumption, exchange, resilience, collaboration and coordination among the supply chain stakeholders both at inter and intra organisational levels, which will help in managing risks to prevent disruptions caused by unexpected and emergency situations characterised by volatile, uncertain, complex and ambiguous business environment (Choi et al., 2019; Kshetri, 2018; Lohmer et al., 2020; Min, 2019; Saberi et al., 2019; Yadav et al., 2020).

\subsection{Knowledge gap}

Research in OSCM have emphasised the applications of BCT in OSCM and smart manufacturing (Esmaeilian et al., 2020), the potential positive and significant impact of BCT on supply chain transparency and business performance (Wamba et al., 2020a), the influence of digital transformation on BCT implementation (Akter et al., 2020), the impact of BCT on supply chain resilience and business model innovation (Wamba et al., 2020b), and the outline of BCT drivers and adoption challenges (Wamba \& Queiroz, 2020). Despite the benefits offered by BCT currently reported in the extant OSCM literature, the Gartner hype cycle shows that the adoption of this technology is at a nascent stage (current in the early adopter stage), which means that the implementation within business organisations is still approximately ten years away from demonstrating transformational business impact (Gartner, 2019). In this context, 
OSCM literature has identified challenges pertaining to BCT adoption (Dutta et al., 2020; Hastig \& Sodhi, 2020; Wamba et al., 2020b; Yadav et al., 2020). Two barriers which have consistently appeared in the literature are: (1) lack of guidelines and strategy informing managers on the blockchain adoption process (Angelis \& Silva, 2019); (2) limited understanding about the factors that will influence the adoption behaviour of the decision-makers (such as operations and risk managers, and senior management) within the organisations for specific use-cases (such as risk, information, process, resource, procurement and transaction management), which will facilitate them to develop and implement a BCT strategy (Bai et al., 2020; Clohessy \& Acton, 2019).

\section{Research question}

The existing research examining and understanding the use of BCT in risk management to prevent operations and supply chain disruptions is extremely limited. Few articles have reported the significance of BCT in risk management (Alkhudary et al., 2020; Choi et al., 2019; Saberi et al., 2019), but they do not provide any empirical insights. In this context, while few studies have examined the factors influencing the adoption of BCT in OSCM (Wong et al., 2020a; 2020b; Wamba et al., 2020b; Queiroz et al., 2020; Queiroz \& Wamba, 2019; Kamble et al., 2018), there have been no studies reported so far which have examined the antecedents of BCT adoption from the perspective of operations managers to manage risks in business operations and supply chain processes either in developed or developing economies (Queiroz et al., 2019). The overarching objective of this paper is to bridge this knowledge gap in the OSCM literature concerning the adoption of BCT to manage risks, which leads to the following research question motivating our current research: What are the factors that drive the intention to use blockchain technology for managing risks in OSCM within the organisations, from the perspective of operations managers?

\subsection{Contribution}

The knowledge gap addressed in this research is important because OSCM scholars and practitioners have indicated and acknowledged the increasing use and impact of BCT to create business value and capture this value by gaining competitive advantage (Dubey et al., 2020). The significance of using emerging technologies such as BCT (Akter et al., 2020), artificial intelligence (Grover et al., 2020), cloud computing (Khayer et al., 2020a; 2020b), big data (Araz et al., 2020) and digital twins (Gölzer \& Fritzsche, 2017), is well articulated and clear in the extant OSCM literature. This study employs an overarching theoretical lens based on VUCA business environment (Baran \& Woznyj, 2020; Bennett \& Lemoine, 2014), technology acceptance model (TAM) (Davis, 1989) and organisational resilience (Min, 2019; Melnyk et al., 2014; Burnard \& Bhamra, 2011), extending and building upon the emerging BCT adoption literature, to develop and test a conceptual model that will help to understand and explain the factors influencing BCT adoption for risk management. Therefore, this study will provide the OSCM community with empirical evidence which will lead to a better understanding on the adoption behaviour of operations managers with regards to using BCT for managing risks and increasing supply chain resilience. The paper also contributes to enriching the OSCM literature in the context of emergent technology adoption by providing a decision-framework that will help operations managers to assess the feasibility and relevant 
of BCT adoption in risk management, which is also currently less developed in the OSCM literature.

\section{Summary}

Accordingly, to answer our research question: Firstly, we will consolidate the literature on BCT applications and BCT adoption to describe the knowledge gap in the OSCM literature. Secondly, we will derive theoretical constructs from the BCT adoption literature to develop a conceptual model that will examine the antecedents influencing the intention to adopt the technology for managing risks. Thirdly, we will design a survey instrument to capture data from the operations managers in the UK, which will be used to test and validate the conceptual model. Fourthly, we will employ the Structural Equation Modelling (SEM) statistical technique to process the data and test the hypothesis derived from the proposed conceptual model. Exploratory factor analysis will be used to examine the validity of the constructs and latent variables, and SEM path analysis will demonstrate the casual relationships between the research constructs. Finally, we will propose a decision framework that will help to assess the feasibility, relevance and usefulness of BCT adoption in risk management.

The paper is structured as follows. Section 2 provides an overview of the literature pertaining to BCT applications and adoption, followed by the conceptual model development discussed in the Sect. 3. The methodology employed to collect data from operations managers and test the model using SEM statistical analysis is presented in Sect. 4. The results of the SEM analysis are presented in Sect. 5 and further discussed in Sect. 6. BCT decision framework is also presented in the Sect. 6, followed by the theoretical and practical implications of our research in Sect. 7. Finally, conclusions are presented along with the limitations of the study and an agenda shaping the future direction of research in this emerging and unexplored domain of BCT adoption in Sect. 8.

\section{Literature review}

The ongoing discussion regarding BCT in OSCM and other management sectors such as humanitarian logistics, marketing, finance and human resource, has primarily focussed on the value and benefits offered by the features of the technology. The existing studies have also investigated the impact of BCT in supply chain primarily focussing on business performance, product and service traceability to enhance transparency, quality management and risk reduction, anti-counterfeiting, transaction efficiency, raw material procurement and distribution to consumers, and business process re-engineering. Prior works have also theoretically examined the underlying drivers and barriers from management strategy, technology integration, market pressure, regulations and skills perspectives. A key theme that has emerged from the existing OSCM research is factors influencing and inhibiting BCT adoption in business organisations. Therefore, in the past couple of years, few studies have followed this research direction to empirically provide insights to the OSCM community regarding the BCT adoption behaviour from the perspective of supply chain professionals, which is further reviewed below. 


\subsection{Blockchain adoption}

The adoption of blockchain in OSCM is still at its infancy (innovator stage according the diffusion of innovation theory) (Gartner, 2019), therefore researchers are dedicating significant efforts to understand the behavioural intention to adopt BCT drawing from the literature on technology acceptance models (Wamba \& Queiroz, 2020; Dutta et al., 2020; Orji et al., 2020; Kouhizadeh et al., 2020).

Wong et al. (2020a) have developed a model deriving constructs such as performance expectancy, effort expectancy, facilitating conditions, technology readiness, technology affinity, and trust in the technology from the (UTAUT) model. The data captured from 200 firms in Malaysia demonstrated that the behavioural intention to adopt is positively and significantly impacted by facilitating conditions (i.e. availability of technical and knowledge support), technology readiness of the firm (digitalisation and digital transformation in the firm), and technology affinity (i.e. willingness to actively engage with the technology, cope with it and exhibit optimistic behaviour towards the technology). Another study reported in Wong et al. (2020b) adopted the Technology, Organisation and Environment Framework (TOE) to examine the adoption of blockchain that will support operational processes and supply chain business practices among the SMEs in Malaysia. The results showed that pressure from competition in the market, the implementation complexity, financial resources, and relative sustainable advantage significantly and positively impact the intention implement and use BCT in business operations. However, market dynamics, regulatory support (with regards to BCT adoption and implementation) and organisational leadership/support from senior management did not impact the behavioural intention.

The adoption of BCT in Indian supply chain was reported in Kamble et al. (2018). The conceptual model for the study was developed by combining technology acceptance model (TAM), technology readiness index (TRI) and the theory of planned behaviour (TPB) to examine the behavioural intention to use BCT. The validation of the model with 181 supply chain professionals representing 102 companies demonstrated that perceived usefulness of the technology and attitude of the users (measured as a function of perceived usefulness and perceived ease of use) will significantly impact intention to use and adopt BCT. Kamble et al. (2020) modelled the factors influencing the adoption of BCT in Indian supply chain by deriving constructs from Technology Acceptance Model and Technology-organisationEnvironment framework. The findings indicated that perceived usefulness, perceived ease of use (TAM factors) and competitive pressure from the market (external environment construct) will significantly impact the intention to adopt BCT. Few constructs derived from TOE, such as technical knowledge, training and education and readiness of partners/business stakeholders significantly and positively impacted the TAM factors and intention to adopt BCT.

Wamba et al. (2020b) have developed a model to examine the impact of knowledge sharing (derived from knowledge-based view theory) and trade partner pressure (derived from institutional theory) on blockchain adoption, and thereby the impact of BCT adoption on supply chain transparency and performance in India and US. The study therefore integrated the literature on technology adoption and supply chain performance and found that knowledge sharing, and external pressure will positively impact the adoption of BCT, and the supply chain performance will be significantly influenced through the adoption and transparency offered by the technology. Queiroz et al. (2020) also examined the BCT adoption among supply chain professionals in Brazil by developing a model, where research constructs were derived from UTAUT. The results showed that effort expectancy, facilitating conditions, trust and social influence (external competitive environment) will significantly 
and positively influence the behavioural intention to adopt BCT. Queiroz and Wamba (2019) reported a model by combining supply chain and network theory, TAM and UTAUT models to understand and examine the factors affecting intention to adopt BCT and expectations of the end user (business perspective) in the logistics and supply chain field in India and the US. The results showed that BCT adoption is at an early stage in these countries, performance expectancy and facilitating conditions are good indicators for the intention to adopt BCT, however, the conditions and influencers vary in each country, which can be attributed to economic situation, regulations and market dynamics.

\subsection{BCT applications}

Many applications of BCT have been reported in the recent OSCM literature. We have summarised several applications in Table 1. We found that although the features offered by the BCT can be valuable for risk management, its use in this context is still nascent.

In the context of BCT adoption, the review of BCT current applications in OSCM shows the key dimensions to assess the feasibility of BCT adoption, which are: (1) need of a shared information repository; (2) need for objective and immutable data within the repositories; (3) information sharing between multiple stakeholders in different geographical locations; (4) improving information discoverability; (5) eliminating dependence on intermediaries; (6) reducing transaction costs and efforts; (7) need for a decentralised communication mechanism; (8) need for a trust less information sharing and update mechanism..

\subsection{Blockchain strategy}

Recent studies have outlined and reported the positive impact of BCT in OM and many industries such as manufacturing, logistics and airline (Cole et al., 2019; Lohmer, 2019). This impact is further boosted by the digital transformation, Industry 4.0 and Intelligent Internet of things (IIoT) trends in the industry. This has led to the emergence of smart factories and autonomous supply chain management (Akter et al., 2020), where BCT can add value not only in enhancing the visibility of the processes, but sustainable collaboration through real-time data and information sharing among the stakeholders (Babich \& Hilary, 2020).

Despite the positive outlook about BCT, its adoption has been scarce in these industries (except in financial sector) due to lack of understanding, implementation strategy and longterm sustainability and resilience offered by the technology in different business environment (Dutta et al., 2020). Recent research in OSCM examining the capabilities and benefits of BCT, and its current implementation practices have indicated lack of organisational strategy, knowledge sources and framework outlining the need and feasibility of BCT in various contexts are potential barriers to wide-scale adoption in business environment (Cole et al., 2019; Hughes et al., 2019; Pournader et al., 2020; Saberi et al., 2019; Wang et al., 2019). For example, although professionals' value the potential of the BCT and its potential to disrupt and optimise the existing business practices, they have little understanding of the BCT, its capabilities and limitations in specific business process contexts. Furthermore, studies have also showed that supply chain professionals are uncertain and uncertain about the value offered by BCT compared to the existing technologies, which are being used in the business environment (Langley, 2018). In this context, Angelis and Silva (2019) have outlined the emerging need to investigate BCT strategy and decision frameworks that will facilitate business managers to become familiar with the technology, understand its usefulness and 
Table 1 Blockchain applications

\begin{tabular}{|c|c|c|c|}
\hline Organisation & Domain of use & Application of blockchain & $\begin{array}{l}\text { Usefulness and } \\
\text { relevance }\end{array}$ \\
\hline Walmart & Food Retail & $\begin{array}{l}\text { Provide consumers the } \\
\text { information about the } \\
\text { origin of the products at } \\
\text { the farm level and } \\
\text { streamline the } \\
\text { restocking process. } \\
\text { Increasing food trust } \\
\text { among the consumers, } \\
\text { and advocating its } \\
\text { importance in the food } \\
\text { supply chain }\end{array}$ & $\begin{array}{l}\text { Product tracing and } \\
\text { tracking from farm } \\
\text { to fork to advocate } \\
\text { food trust among } \\
\text { consumers }\end{array}$ \\
\hline Maersk & Shipping and logistics & $\begin{array}{l}\text { Managing cargo remotely, } \\
\text { track the movement of } \\
\text { the cargo and reduce the } \\
\text { waiting time by } \\
\text { eliminating paper } \\
\text { transactions in the } \\
\text { destination port }\end{array}$ & $\begin{array}{l}\text { Process optimisation } \\
\text { and efficiency in } \\
\text { International goods } \\
\text { movement }\end{array}$ \\
\hline British Airways & Airline & $\begin{array}{l}\text { Streamline and efficiently } \\
\text { present the information } \\
\text { about flights accurately } \\
\text { and consistently across } \\
\text { multiple } \\
\text { platforms-Website, } \\
\text { airport gate monitors } \\
\text { and the mobile apps }\end{array}$ & $\begin{array}{l}\text { Information accuracy } \\
\text { across multiple } \\
\text { platform, } \\
\text { concurrently }\end{array}$ \\
\hline DHL & $\begin{array}{l}\text { Logistics and } \\
\text { pharmaceutical }\end{array}$ & $\begin{array}{l}\text { In collaboration with } \\
\text { Accenture (technology } \\
\text { provider) reduce } \\
\text { tampering or } \\
\text { counterfeiting drug } \\
\text { issues in the pharma } \\
\text { industry, strategic } \\
\text { alignment between the } \\
\text { product manufacturing } \\
\text { and its movement } \\
\text { within the supply chain }\end{array}$ & $\begin{array}{l}\text { Information resilience } \\
\text { among the } \\
\text { stakeholders is } \\
\text { facilitated through } \\
\text { transparency, } \\
\text { traceability and } \\
\text { trackability }\end{array}$ \\
\hline Fedex & $\begin{array}{l}\text { Logistics and customer } \\
\text { relation }\end{array}$ & $\begin{array}{l}\text { Store the data gathered } \\
\text { from sensors and the } \\
\text { customers to quickly } \\
\text { resolve customer issues } \\
\text { and disputes, by using } \\
\text { permissioned ledgers } \\
\text { among the various } \\
\text { actors in the supply } \\
\text { chain }\end{array}$ & $\begin{array}{l}\text { Information } \\
\text { aggregation through } \\
\text { BCT platform has } \\
\text { led to better } \\
\text { co-ordination and } \\
\text { collaboration } \\
\text { among the various } \\
\text { stakeholders to } \\
\text { enhance customer } \\
\text { experience and } \\
\text { satisfaction }\end{array}$ \\
\hline
\end{tabular}


Table 1 (continued)

\begin{tabular}{|c|c|c|c|}
\hline Organisation & Domain of use & Application of blockchain & $\begin{array}{l}\text { Usefulness and } \\
\text { relevance }\end{array}$ \\
\hline $\begin{array}{l}\text { Abu Dhabi National Oil } \\
\text { Company }\end{array}$ & $\begin{array}{l}\text { Oil and gas supplier } \\
\text { management }\end{array}$ & $\begin{array}{l}\text { Managing the intergroup } \\
\text { network (of } 14 \\
\text { companies) involved in } \\
\text { the extraction, } \\
\text { processing, } \\
\text { transportation, sales and } \\
\text { marketing of oil and } \\
\text { gas, for real-time } \\
\text { accounting and } \\
\text { providing full } \\
\text { transparency to } \\
\text { shareholders in a secure } \\
\text { manner }\end{array}$ & $\begin{array}{l}\text { Increase collaboration } \\
\text { and partnership } \\
\text { between the supply } \\
\text { chain actors for } \\
\text { responsible } \\
\text { consumption and } \\
\text { production }\end{array}$ \\
\hline De Beers & Jewellery and diamond & $\begin{array}{l}\text { Track the origin of } \\
\text { diamonds from mining } \\
\text { to the retail store, to } \\
\text { help regulate the supply } \\
\text { chain }\end{array}$ & $\begin{array}{l}\text { Transparency in } \\
\text { production, } \\
\text { advocating decent } \\
\text { work and } \\
\text { responsible } \\
\text { practices }\end{array}$ \\
\hline $\begin{array}{l}\text { Louis Dreyfus } \\
\text { Company (LD }\end{array}$ & $\begin{array}{l}\text { Food retail (bottling } \\
\text { process) }\end{array}$ & $\begin{array}{l}\text { Increase collaboration } \\
\text { between the supply } \\
\text { chain actors, and } \\
\text { introduce technology } \\
\text { intermediary to track, } \\
\text { trace and employ } \\
\text { responsible recycling in } \\
\text { the bottling process of } \\
\text { juices }\end{array}$ & $\begin{array}{l}\text { Advocating } \\
\text { environmental } \\
\text { sustainability to } \\
\text { reduce plastic waste } \\
\text { and carbon } \\
\text { emissions }\end{array}$ \\
\hline Moyee Coffee & $\begin{array}{r}\text { Exotic coffee } \\
\text { distribution }\end{array}$ & $\begin{array}{l}\text { Fair chain for the coffee } \\
\text { industry by digitising } \\
\text { the supply chain to be } \\
\text { able to track the first } \\
\text { mile (farmers) and last } \\
\text { mile (consumers) }\end{array}$ & $\begin{array}{l}\text { Providing full } \\
\text { transparency in the } \\
\text { payment system, in } \\
\text { addition to evidence } \\
\text { of the product } \\
\text { quality }\end{array}$ \\
\hline Cepham & $\begin{array}{l}\text { Nutritional ingredient } \\
\text { supply }\end{array}$ & $\begin{array}{l}\text { Assess the quality of the } \\
\text { products before they are } \\
\text { consumed by the } \\
\text { customers to alleviate } \\
\text { risks of product quality }\end{array}$ & $\begin{array}{l}\text { Product quality } \\
\text { management in the } \\
\text { supply chain }\end{array}$ \\
\hline Uni Lever & $\begin{array}{l}\text { Tea production and } \\
\text { distribution }\end{array}$ & $\begin{array}{l}\text { Maintain supply chain } \\
\text { relationships and } \\
\text { associated } \\
\text { documentation in the } \\
\text { tea sector, to maintain } \\
\text { product quality and in } \\
\text { line with the CSR } \\
\text { objectives of the } \\
\text { company }\end{array}$ & $\begin{array}{l}\text { Digitalisation and } \\
\text { disintermediation } \\
\text { have resulted in } \\
\text { reduced transaction } \\
\text { costs and enhance } \\
\text { quality management } \\
\text { of the raw materials, } \\
\text { product } \\
\text { manufacturing }\end{array}$ \\
\hline
\end{tabular}


Table 1 (continued)

\begin{tabular}{llll}
\hline Organisation & Domain of use & Application of blockchain & $\begin{array}{l}\text { Usefulness and } \\
\text { relevance }\end{array}$ \\
\hline Ford & $\begin{array}{c}\text { Raw material } \\
\text { production in } \\
\text { automotive industry }\end{array}$ & $\begin{array}{l}\text { Tracing and tracking of } \\
\text { raw material such as } \\
\text { cobalt used to } \\
\text { manufacture parts of the } \\
\text { car in the industry }\end{array}$ & $\begin{array}{l}\text { Responsible raw } \\
\text { material mining, } \\
\text { manufacturing and } \\
\text { consumption } \\
\text { practices for } \\
\text { environmental } \\
\text { sustainability }\end{array}$ \\
\hline
\end{tabular}

value in different contexts of use, and define the business goals of using the technology by assessing the limitations of BCT compared to the existing mechanisms (currently used in the industry for addressing the same issues). A report compiled by Juniper Research (2017) has suggested to first assess suitability of BCT by comparing it to existing solutions (mechanisms currently used), to understand whether the use of this emerging technology will provide not only in terms of throughput, but also in terms of economic performance (i.e. whether alternative solutions are cheaper and will require less disruptions and changes across the business processes and practices) (Holden \& Moar, 2017).

Blockchain strategic initiatives will help organisations and the OSCM community to understand how BCT can be adopted, implemented and used in the business organisations to create and capture business value and achieve sustainable competitive advantage (Bai et al., 2020; Carson et al., 2018; Felin \& Lakhani, 2018; Min, 2019). Angelis and Silva (2019) have contributed to the ongoing discussion regarding the BCT adoption by proposing blockchain value driver-focused framework. The framework provides managers with a systematic method for assessing the suitability of blockchain adoption by integrating the dimensions value creation, feasibility of BCT to create value and integration of BCT with other technologies to realise the value. This is by far the only reported work which has contributed to the discussion concerning BCT adoption strategy. Although, BCT is innovative and unique, and there has been substantial interest and not necessarily adoption of this technology, the benefits offered by the technology is not just dependent its implementation, but a strategy guiding the implementation process and a decision framework, which will help to assess and understand the feasibility of its application within various contexts aligned to the goals and priorities of the business organisations.

The review clearly outlines that most of the current BCT research in the OSCM literature focuses on a how BCT is being or can be applied for a broad range of organisational functions, its impact on the organisational performance, dynamic capability, supply chain transparency and collaboration among the stakeholders and trade partners. Examining and understanding the factors influencing the adoption of BCT in OSCM is still at a nascent and emerging stage within the academic research. Furthermore, the studies have showed the significance of constructs derived from UTAUT, TAM and Institutional theories more than TOE and other models, to predict behaviour intention to adopt the technology. Although, research examining the use of BCT in OSCM literature is progressing at a rapid pace, there has been paucity of empirical evidence examining the intention to adopt BCT is OSCM by the operations managers for managing risks during unexpected situations (such as crisis, disasters, pandemic and business process failures etc.). 
Recently, BCT adoption framework has emerged as a research theme in the literature. In this context, existing literature have systematically reviewed the extant literature to identify the drivers and barriers related to BCT adoption, and developed frameworks that is likely to facilitate utilizing BCT in different business contexts. Using Koppenjan and Groenwegen's (2005) institutional framework, Janssen et al., (2020), have proposed PIMT (Process, Institutional, Markets and Technology) framework for BCT adoption. The authors have considered change strategies and instruments to implementing change, regulations, legislation and governance, the organisational culture and innovation mindset, internal business processes and external business environment, and digital shared information infrastructure, as key dimensions to BCT adoption. Toufaily et al., (2021) have also investigated the challenges and implications concerning adoption of BCT in the United Arab Emirates (UAE) public and private sectors. Based on the findings stemming from semi-structured interviews conducted with stakeholders, authors have developed a conceptual framework which will facilitate BCT implementation in the UAE. The framework considers technology infrastructure challenges-immature technology, access to capital, interoperability and complexity, environmental challenges - business ecosystem readiness, and regulatory uncertainty, and internal organisational challenges - business model alignment, governance, and top management support. Clohessy et al., (2020), have developed a BCT adoption framework adopting a theoretical lens by systematizing academic input comprising of information technology (IT) innovation adoption (Rogers, 2010), TOE (technology-organization-environment, Baker, 2012), theory of task-technology fit (TTF, Zigurs \& Buckland, 1998), the technology acceptance model (TAM, Davis, 1989), and and the unified theory of acceptance and use of technology (UTAUT, Venkatesh et al., 2016). The framework considers that the role of individuals (skills, knowledge, and competencies) and impact of task design, individual roles and responsibilities, are critical to effectively and successfully adopt BCT. Along similar lines, Balasubramanian et al. (2021), proposed a blockchain readiness assessment framework, and assessed the readiness of UAE healthcare sector using the framework and found that: (1) government initiatives will drive BCT adoption; (2) regulation and legislative uncertainty inhibits adoption in all firms, while large firms are more committed to pilot BCT project investments. The framework considers strategic relationship between stakeholders, facilitating conditions stemming from regulatory and legal certainty and both supportive technical as well organisational infrastructure, and motivational as well as engagement readiness of the organisations, as key drivers for putting BCT into practice. These frameworks theoretically demonstrate that adoption of BCT requires the consideration of a broad range of internal organisational factors, decision makers' perception (usefulness and ease of use), external market environment (stakeholder readiness and regulatory certainty), over and above the technology infrastructure and digital readiness. Empirical investigations looking at these dimensions either in isolation or combining them will advance BCT scholarship in both operations management and research. In this context, our study empirically investigates the relationship between external business environment characteristics, perceived usefulness, and ease of using the BCT and operational resilience on the intention to adopt BCT from operations managers' perspective for risk management.

\subsection{Blockchain in risk management}

Risk management is defined as a systematic approach to identify, assess and respond to risks to which the organisation is exposed (Kodym et al., 2020). Decision sciences have the potential to enhance risk management in organisations (Covello, 1987). Decision trees have 
been very useful for risk management through the inclusion of decision alternatives with corresponding risk management alternatives (Chelst \& Bodily, 2000), whereas dependence between random variables caused by common risk factors has been included in statistical models for risk analysis (van Dorp, 2005). Operational Research can be valuable to develop tools and techniques to analyse and evaluate risks (Ritchie \& Brindley, 2007), as it provides a set of techniques that can be used in uncertain conditions to balance the mitigation of risks and the cost involved (Rodríguez-Espíndola et al., 2020a; 2020b). That is the reason there has been a surge of contributions focused on risk management in the Operations Research and Management Science subjects, particularly linked to mathematical models, simulation, probabilistic models, network analysis, and decision models (Romero-Silva \& de Leeuw, 2021). The reader is referred to Newman et al. (2017) for a review about decision-support systems for risk reduction and to Romero-Silva and de Leeuw (2021) for review about the application of Operational Research to risk management.

A growing stream of research supporting risk management is looking at the capabilities of emergent technologies. Ivanov et al. (2019) suggests that as digital technologies affect supply chains, and supply chains are affected by risks, it is only logical to assume that there is a link between digital technologies and risk management. Blockchain holds the potential to support the development of a new paradigm of risk management that is more proactive, connected, able to identify intangible risks and to provide multiple layers of protection (Kouhizadeh et al., 2020; Min, 2019), which is the reason there are claims about the value of the risk management field to embrace emergent technologies such as blockchain (Gejke, 2018; Lohmer et al., 2020). Hence, the role of blockchain for risk management has started to be explored on different sectors. It has been suggested that blockchain can be used for credit decisions in the banking sector to reduce information uncertainty (Dashottar \& Srivastava, 2021), for cyber threat intelligence sharing systems for dynamic risk management (Riesco et al., 2020), for prevention of security breaches at the same time as it enhances connectivity between partners (Min, 2019), for information security (Kodym et al., 2020), for ensuring security and privacy of donations for humanitarian operations to mitigate the risk of losing records and transparency (Khan et al., 2021), and for supply chain visibility to provide provenance knowledge and reduce risk perception from consumers for purchasing decisions (Montecchi et al., 2019). Recently, Lohmer et al. (2020) examine the impact of blockchain on resilience strategies using simulation. The paper compares a model with a conventional structure against a model with a collaborative supply chain based on the use of blockchain. Their findings suggest resilience can be improved through the use of blockchain-based collaboration, but they highlight the importance to avoid poor implementation as it can cave counterproductive effects. Indeed, poor implementation can hinder the potential of blockchain and increase risks, endangering the impact of the investment (Kodym et al., 2020). In that sense, less attention has been paid to the perception from users and the antecedents for the implementation of these technologies, which can ultimately affect the success of introducing technologies such as blockchain.

\section{Conceptual model theory development}

Some of the most common models used to examine the intention to adopt BCT and other emerging technologies in the OSCM literature include the Technology Acceptance Model (TAM) (Davis, 1989), the Unified Theory of Acceptance Model (UTAUT) (Venkatesh et al., 2011) and the Technology-Organisation-Environment (TOE) Framework (Pillai \& Sivathanu, 


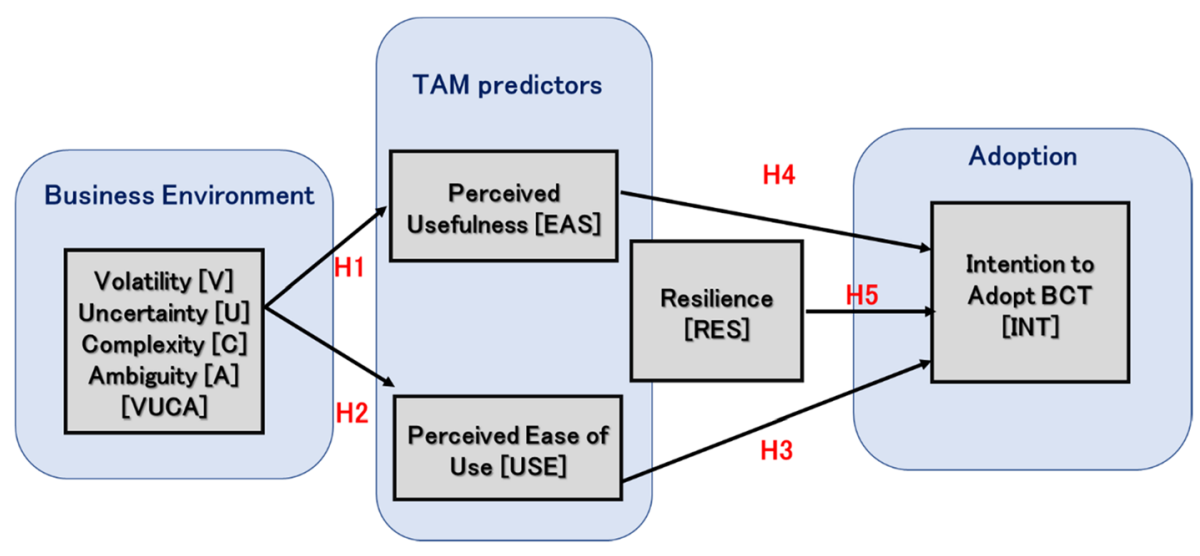

Fig. 1 Theoretical model-BCT adoption in risk management

2020). The review outlined in the previous section clearly demonstrates that constructs derived from the TAM model, i.e. perceived usefulness and ease of using an emergent technology such as BCT, are valuable predictors for modelling and explaining the adoption behaviour (Albayati et al., 2020; Kamble et al., 2018). However, past studies have not studied the impact of a business environment characterised by VUCA on these TAM constructs, which can provide a necessary context to understand the BCT adoption for managing risks in supply chain management (Alkhudary et al., 2020; Dolgui \& Ivanov, 2020; Dutta et al., 2020). In order to complement the past studies on BCT (Wong et al., 2020a; 2020b; Queiroz \& Wamba, 2019) and emerging technology adoption in OSCM, this study will model and examine the casual relationships between VUCA environment (Worley \& Jules, 2020), TAM constructs, resilience and intention to adopt BCT for managing risks. The relationship between constructs is presented in Fig. 1 and further discussed below.

\subsection{VUCA business environment: perceived usefulness of BCT—intention to adopt BCT}

From an OSCM perspective, we define perceived usefulness as the impact of BCT for managing risks to achieve sustainable competitive advantage, as anticipated by the operations managers (Kamble et al., 2020). The research concerning the adoption of BCT reported in the OSCM literature has shown that perceived usefulness of the technology (construct in TAM) has a positive and significant impact on the behavioural intention to adopt the technology (Wong et al., 2020a; 2020b). Research in the OSCM domain examining adoption of other emerging technologies such as artificial intelligence (Grover et al., 2020), cloud computing (Khayer et al., 2020a; 2020b) and big data (Verma et al., 2018) have reported similar findings, which makes perceived usefulness a significant influencer to adopt emerging technologies. However, the perceived usefulness of a technology from an operations manager's perspective will be influenced by the context of its use, i.e. why the technology will be used, and benefits of using the technology in that given context. In this context of use, from the perspective of an operations manager, BCT adoption can improve visibility across the supply chain through enhanced transparency, which can facilitate risk identification at an early stage, and periodic risk reviews once risk mitigation strategies have been implemented (Wamba et al., 2020b; 
Zwitter \& Boisse-Despiaux, 2018). The influence of an emergency or unexpected business environment on perceived usefulness to implement BCT, and how it will impact the adoption behaviour is currently unknown and we believe it will be a good starting point in OSCM research to focus on a specific use-case for technology adoption which is highly acknowledged and significant, i.e. risk management, for adding value to planning and strategizing business operations. This leads us to the following research hypotheses about the relationship between VUCA business environment, perceived usefulness of BCT and intention to adopt $\mathrm{BCT}$ for risk management to prevent disruptions and increasing process reliability in the business organisations.

H1 VUCA business environment will significantly influence the perceived usefulness of blockchain technology for managing risks.

H2 Intention to adopt blockchain technology for managing risks in a VUCA business environment will be significantly influenced by perceived usefulness of the technology in that context.

\subsection{VUCA business environment: perceived ease of using BCT-intention to adopt BCT}

Perceived ease of using a technology is a construct which is derived from TAM, UTAUT and theory of reasoned actions (TRA), and has been widely used to study the adoption of emerging technologies in the view of optimising business operations and processes (Karamchandani et al., 2020; Nuryyev et al., 2020). This construct is demonstrated as a significant influencer to predict the intention to adopt emerging technologies such as BCT, in OSCM. The ease of using a technology is guided by an individual's perception about the effort required to effectively and efficiently use it for a specific purpose and for the context. Purpose and context facilitate understanding the effort required to use the technology, despite of the knowledge, skills and trust required by the individuals in the technology (which has been examined in the extant literature) (Rodríguez-Espíndola et al., 2020a; 2020b). For example, in the case of managing operational risks (clearly defined by the context of it use), the main purpose of using the technology is to help prevent and combat the negative effects on operational processes anticipated from a VUCA situation (Tsolakis et al., 2020). This will help the organisations remain productive, mitigate operational issues, and gain competitive advantage by dynamically adapting to the needs of the business environment. From an operations manager's perspective, BCT offers a trust less and secure environment facilitating automated real-time information sharing and collaboration among the supply-chain stakeholders. This is accomplished through a decentralised and distributed digital ledger, which will facilitate analysing the risk and responding to it dynamically through collaborative, co-ordinated and visible efforts of all the stakeholders in the supply chain processes (Akter et al., 2020; Alkhudary et al., 2020; Choi et al., 2019). The impact of context on the perceived ease of use to model the behavioural intention is understudied in the current OSCM literature, thus it is still unknown (Angelis \& Silva, 2019). This leads us to the following research hypotheses to understand the relationship between VUCA business environment, perceived ease of using BCT and intention to adopt BCT for managing risks to prevent and manage disruptions in supply chain.

H3 VUCA business environment will significantly influence the perceived ease of using blockchain technology for managing risks. 
H4 Intention to adopt blockchain technology for managing risks in a VUCA business environment will be significantly influenced by perceived ease of using the technology in that context.

\subsection{Intention to adopt BCT: resilience}

Resilience has received significant academic attention in the last two decades in supply chain and operations management. It is valuable to help businesses plan, prepare, strategize operations and respond to unpredictable disruptions caused by either natural or man-made causes, and efficiently recover from such disruptions (Macdonald et al., 2018; Scholten et al., 2019; Sheffi, 2007; Stevenson \& Busby, 2015). The existing research in this area has demonstrated the positive impact of emerging technologies such as big data, artificial intelligence, blockchain, cloud computing and virtual reality to manage risks within autonomous and IoT-enabled supply chain. Nevertheless there is lack of empirical insights to guide decisionmakers (de Sá et al., 2019; Dufour et al., 2018; Scholten \& Schilder, 2015). The adoption of BCT can facilitate information sharing, collaboration between multiple stakeholders, coordinated responses and mitigation strategies among the stakeholders to prevent operational failures and enhance service reliability, and data-driven decisions to optimise and reconfigure operational processes and resources (Wamba et al., 2020b; Sternberg et al., 2020). This increases the capability of the organisations to dynamically and quickly adapt to a VUCA environment by monitoring risks and responding with a strategy, which will make the business processes resilient to unexpected disruptions (Millar et al., 2018). Although resilience in business operations and supply chain activities holds paramount importance for operations managers in any situation (Rubbio et al., 2019), the impact of resilience on the intention to adopt BCT has never been modelled and empirically examined in the current OSCM literature. This leads us to our final hypothesis.

H5 Intention to adopt blockchain technology for managing risks in a VUCA business environment will be significantly influenced by organisational resiliency.

\section{Methodology}

This paper investigates the factors affecting the potential implementation of blockchain in risk management adopting a primary research methodology employing survey method (Green et al., 2012; Wamba et al., 2020b; Wong et al., 2020a). To understand the BCT adoption, information from 116 operations managers in the UK has been gathered and structural equation modelling has been used to analyse the relationships between different constructs in our proposed research model (Fig. 1). This section will discuss the process employed to gather data and analyse it.

\subsection{Design of the survey}

The data collection instrument was designed looking at the different constructs affecting the readiness and adoption of blockchain to enhance risk management in organisations. Surveys are a useful and economical way to gather information analyse it using statistical methods to analyse the relationships between different variables (Saunders et al., 2015). The 
questionnaire was developed through careful review of the literature to identify the constructs and scales necessary to test the hypothesis proposed. The items were prepared using a 5-point Likert scale $(1=$ completely disagree; $2=$ disagree; $3=$ neither agree nor disagree; $4=$ agree; $5=$ completely agree). The survey was pre-tested with 3 academics and revised by the research team to incorporate changes.

\subsection{Sample selection}

The recent advent of emergency technologies in the UK made it suitable to perform the study. The country has developed a strategy for leveraging emergent technologies in industry (https://tinyurl.com/y2jngwn5) and it has developed programmes promoting the use of emergent technologies to enhance the skillset of organisations (https://tinyurl.com/yyjpmzx3). The UK is constantly moving towards a digital transformation with widespread guidance and support for the adoption of emergent technologies, which is the reason this research is interested in looking into the aspects affecting user-acceptance of emergent technologies for risk management.

Inclusion criteria was incorporated as a set of screening questions in the survey to ensure that that all participants: (1) had at-least one-five years of experience in risk management; (2) were employed in a managerial position; (3) had knowledge and understanding about blockchain technology and its potential use in risk management; (4) were part of an organisation involved in digital transformation initiatives to digitalise business processes. The purpose was to have respondents with first-hand knowledge and the capacity to make decisions that could deliver meaningful information for this study.

\subsection{Data collection}

Blockchain is quickly becoming an interesting alternative for supply chain managers. However, it is important to recognise the factors affecting its adoption to exploit the potential benefits offered by this technology. This research has used purposive sampling involving managers with first-hand knowledge about the use of technology in operations, which is similar to the strategy employed in existing studies on BCT adoption (Wong et al., 2020a; 2020b). Respondents included operations managers, risk managers and crisis managers in companies operating in the UK (Figs. 2 and 3). For data collection, an online survey questionnaire was set-up digitally by the authors and administered by Qualtrics (www.qualrics. com), adhering to the inclusion criteria. Data was collected between July 2020 and August

Fig. 2 Role of managers (sample selected)

\section{Role of Managers in the Organisation}

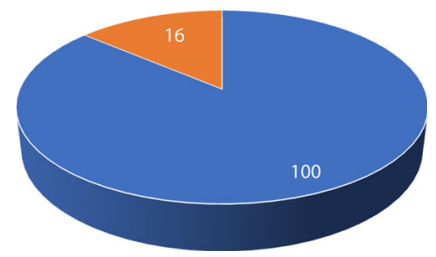


Fig. 3 Managers' years of experience (sample selected)
Years of Managerial Experience

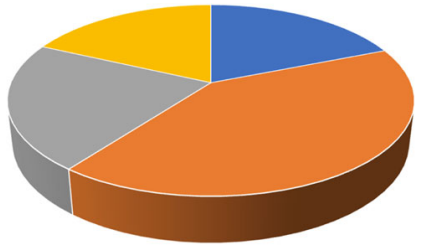

- More than a year $\approx \mathbf{2 - 5}$ years $\approx \mathbf{5 - 1 0}$ years $\approx$ More than 10 years

2020 in the UK (amidst the COVID-19 pandemic). The structured questionnaire used in this research can be seen in Appendix I. Following recommendations from Wolf et al. (2013) and Sideridis et al. (2014), for a model with strong factor links and medium complexity, the questionnaire was applied to 116 managers in the UK to gather their insights. The data was captured anonymously in the platform and prepared for analysis using SEM.

\subsection{Data analysis}

Structural equation modelling (SEM) is a statistical modelling method broadly used in behavioural sciences to analyse the relationships between constructs (Dadeliene et al., 2020). It has the advantage that variables can be measured directly, latent (i.e. not directly measured) or a combination of both (Kalapouti et al., 2017). SEM has been used to test the different hypothesis presented in the model proposed to identify significant relationships and discuss the findings. The assessment of the model proposed and its fit to the data will be tested using goodness-of-fit measures. Typical thresholds used in this study includes, goodnessof-fit index coefficients (GFI), Tucker-Lewis Index (TLI), and comparative fit index (CFI) with good fit considered for values above 0.9 (Doll et al., 1994; Malesios et al., 2018), and root mean square error of approximation (RMSEA) values considered acceptable below 0.08 (Hair et al., 2013). The $\chi 2 /$ df ratio is advised to be under 3 (Kamble et al., 2018). Additionally, reliability of the scales used in the model has been tested using Cronbach's alpha with a threshold of 0.6 as suggested by Hair et al. (2013).

\section{Analysis of results}

\subsection{Measurement model}

Once the data was captured using the survey, a database was created with the 116 responses collected for analysis. Since the survey was applied to a single respondent per organisation, the common method variance was acknowledged as a possibility (Cao et al., 2010). Harman's single-factor test was undertaken to dismiss the possibility of common variance. The process included running an exploratory factor analysis (EFA) and looking at the unrotated solution to determine the number of factors to account for variance (Podsakoff et al., 2003). The variance explained by one factor is $42.2 \%$, which is not the majority of the total variance, meaning that there is no common variance. 
Table 2 Reliability and discriminant validity

\begin{tabular}{llll}
\hline & $\alpha$ & CR & AVE \\
\hline EAS & 0.873 & 0.848 & 0.584 \\
USE & 0.830 & 0.848 & 0.583 \\
VUCA & 0.894 & 0.865 & 0.617 \\
RES & 0.804 & 0.870 & 0.692 \\
INT & 0.932 & 0.884 & 0.657 \\
\hline
\end{tabular}

Using the EFA, Table 2 reports the results the analysis of reliability and discriminant validity of each one of the constructs used in the analysis. All of the Cronbach's alpha coefficients and composite reliabilities values were above 0.8 , and along with the AVE values above 0.5 exhibit adequate reliability and consistency of the constructs included for analysis (Albayati et al., 2020; Hair et al., 2013; Wong et al., 2020a; 2020b).

AMOS was the software selected for analysis, using the maximum likelihood method. Table 3 shows the loadings of the different links in the structural equation model. All the coefficients are over 0.68 , with very good loadings across the different constructs, which are considered acceptable in the area (Queiroz \& Fosso-Wamba, 2019).

Table 3 Factor loadings

\begin{tabular}{|c|c|c|c|c|c|}
\hline & EASE & USE & VUCA & RES & INT \\
\hline Ease_BC_1 & 0.782 & & & & \\
\hline Ease_BC_2 & 0.794 & & & & \\
\hline Ease_BC_3 & 0.794 & & & & \\
\hline Ease_BC_4 & 0.825 & & & & \\
\hline Useful_BC_1 & & 0.700 & & & \\
\hline Useful_BC_3 & & 0.792 & & & \\
\hline Useful_BC_4 & & 0.754 & & & \\
\hline Useful_BC_5 & & 0.724 & & & \\
\hline VUCA_1 & & & 0.730 & & \\
\hline VUCA_2 & & & 0.900 & & \\
\hline VUCA_3 & & & 0.823 & & \\
\hline VUCA_4 & & & 0.854 & & \\
\hline Org_Res_2 & & & & 0.680 & \\
\hline Org_Res_3 & & & & 0.894 & \\
\hline Org_Res_4 & & & & 0.734 & \\
\hline Intention_BC_1 & & & & & 0.843 \\
\hline Intention_BC_2 & & & & & 0.840 \\
\hline Intention_BC_3 & & & & & 0.882 \\
\hline Intention_BC_4 & & & & & 0.930 \\
\hline
\end{tabular}


Table 4 Goodness-of-fit of the SEM model

\begin{tabular}{llllll}
\hline & CFI & GFI & TLI & RMSEA & $\chi^{2} /$ df ratio \\
\hline Model & 0.971 & 0.861 & 0.967 & 0.048 & 1.264 \\
\hline
\end{tabular}

\subsection{Model fit}

Goodness-of-fit indices were used to assess the fit of the model to the data. Table 4 outlines the results. Coefficients of CFI, GFI, TLI, RMSEA and normed $\mathrm{X}^{2}$ were compared to the thresholds presented in the methodology and deemed the model as satisfactory. Although the value of GFI is below the cut-off point (0.9), this can be attributed to the sample size. The value of 0.861 resembles prior results published which have been found acceptable in this area (Kamble et al., 2018; Karamchandani et al., 2020). Hence, the model proposed was deemed acceptable and used to test the hypothesis presented in Sect. 3.

\subsection{SEM Path Analysis}

SEM path analysis was used to test all the hypotheses proposed in this research. Figure 4 shows the results of SEM path analysis Table 5 summarises the outcome of the hypothesis tested.

Risk management involves the identification, analysis and response to different risks. Hence, risk management accounts for a business environment characterised by volatility, uncertainty, complexity, and ambiguity, which is encapsulated by the VUCA construct. SEM path analysis showed that VUCA positively and significantly influenced perceived usefulness of the BCT for managing risks $(\mathrm{p}<0.001$, loading estimate $=0.570)$, therefore supporting H1. Additionally, perceived usefulness of BCT significantly and positively influences the intention to adopt BCT for managing risks $(\mathrm{p}<0.001$, loading estimate $=0.330)$, supporting $H 2$. The results also showed that VUCA significantly and positively impacts the perceived ease of using BCT for risk management $(\mathrm{p}<0.001$, loading estimate $=0.730)$, supporting H3,

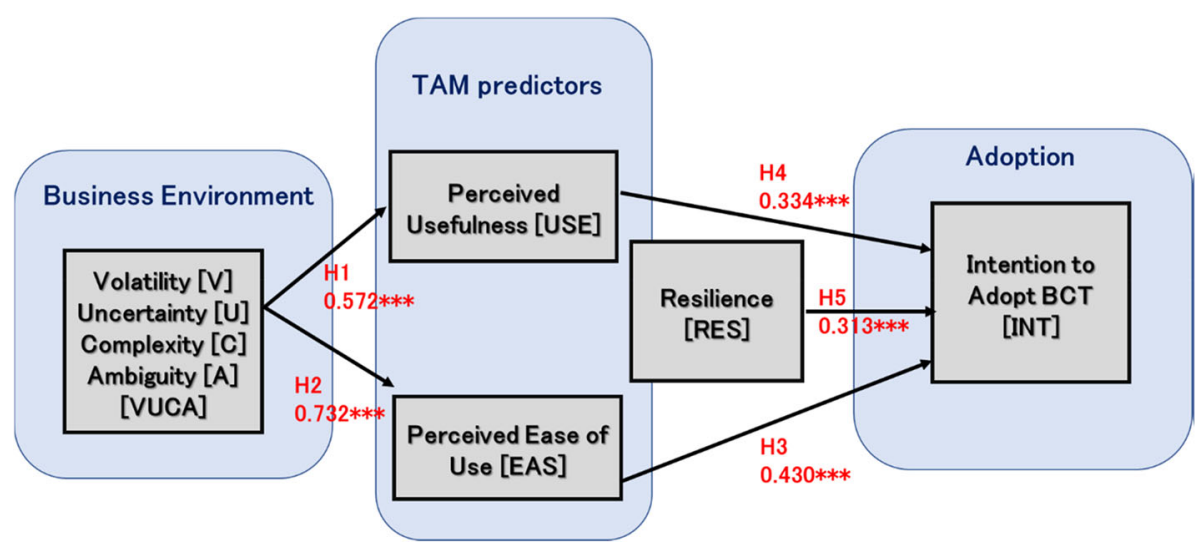

Fig. 4 SEM path analysis 
Table 5 Summary of Hypothesis

\begin{tabular}{lllll}
\hline ID & Hypothesis & Standardised Estimate & Significance & Result \\
\hline H1 & VUCA - USE & 0.572 & $* * *$ & Supported \\
H2 & VUCA - EAS & 0.732 & $* * *$ & Supported \\
H3 & USE - INT & 0.334 & $* * *$ & Supported \\
H4 & EAS - INT & 0.430 & $* * *$ & Supported \\
H5 & RES - INT & 0.313 & $* * *$ & Supported \\
\hline
\end{tabular}

and the intention to adopt BCT is also significantly and positively impacted by the perceived ease of use $(\mathrm{p}<0.001$, loading estimate $=0.430)$, supporting H4. Finally, our findings demonstrated that resilience would also play a significant and positive role to influence the intention of using blockchain for risk management, $(\mathrm{p}<0.001$, loading estimate $=0.310)$, therefore supporting $\mathrm{H} 5$.

\section{Discussion}

\subsection{Findings}

This research examines the adoption of BCT for managing risks in OSCM. Ying et al. (2018) have mentioned that the current state of knowledge about BCT implementation is mostly conceptual, with the need to provide empirical results to support theoretical assumptions. The purpose of this article is to understand the components affecting the adoption of BCT and that can encourage its use for risk management by developing and testing a theoretical model. Harnessing BCT's potential for risk management will allow companies to create more robust systems and become more resilient to disruptions (Rodríguez-Espíndola et al., 2020a; 2020b).

This study confirms that perceived usefulness and easiness of use (constructs that were drawn from the TAM model) are significantly related to the intention of adopting blockchain for risk management. Therefore, the TAM model provides good foundation to examine the adoption of emergent technologies for risk management. Perceived usefulness and perceived ease of use have been related to user acceptance in the past (Davis, 1989). In the context of BCT adoption, the significance of this relationship between perceived usefulness and intention to use blockchain in risk management aligns with findings (reported in different contexts) such as supply chain performance (Kamble et al., 2018), cryptocurrency in finance (Albayati et al., 2020), and tourism and hospitality (Nuryyev et al., 2020). Furthermore, the significant relationship between perceived ease of use and intention to adopt BCT also supports the results reported in Albayati et al. (2020) and Nuryyev et al. (2020). The perceived usefulness of BCT can be attributed to enhanced capability to filter, sort and store data securely, enhanced communication between stakeholders and increased transparency and accountability (Rodríguez-Espíndola et al., 2020a; 2020b; Queiroz \& Fosso-Wamba, 2019). These findings provide evidence regarding the importance of considering the motivation of users for the intention to adopt blockchain in the field of risk management, which means that 
companies most importantly account for the motivation of potential users (e.g., operations managers, crisis managers, risk managers) to support the adoption of blockchain.

An interesting finding is related to the context of risk management. To account for that context and its effect on the intention to adopt blockchain, this research has proposed the VUCA construct. The construct involves volatility, uncertainty, complexity, and ambiguity and it has significant effect on the perceived usefulness and perceived ease of using BCT for risk management. This shows the way managers view the potential of BCT to tackle the different conditions inherent to risk management. The finding suggests that decision-makers and managers consider the dynamic and chaotic context of the activity to decide on the adoption of an emerging technology such as blockchain.

The link between risk and resilience has been highly recognised in the literature (Manhart et al., 2020; Munir et al., 2020). Existing research in this domain has acknowledged the role of people (i.e. individuals and teams, their knowledge and behaviour) as crucial elements to develop resilient business processes and models (Rubbio et al., 2019). Studies have also highlighted that organisational leadership, strategy, resource capacity and human resource capability can facilitate restructuring supply chain operations to deal with unprecedented events (Ambulkar et al., 2015; Polyviou et al., 2019). Emergent technologies have been found to be useful tools to enable supply chain resilience (Dubey et al., 2020; Min, 2019). Nevertheless, there is a lack of evidence about the effect of organisational resilience on the successful adoption of emergent technologies such as BCT. This research is looking at the effect of resilience in the behavioural intention to use blockchain technology for risk management. The relationship was confirmed as significant, meaning that resilient organisations are more likely to invest in this technology for risk management. This result demonstrates evidence about the importance of technology to manage risk and resilience in organisations.

\subsection{Decision framework}

The BCT business strategy must be linked to business goals of an organisation and its effectiveness should be measured using key performance indicators (such as competitive advantage, business economic productivity, process efficiency, employee productivity, consumer engagement and satisfaction and innovation), which are linked to achieving the goals (Angelis \& Silva, 2019). However, the main role of BCT is to support the goals prioritized by the organisation. Understanding the capabilities, scope and limitations of BCT to solve the business problems is key to developing this strategy, which must be driven by potential impact of implementing BCT in a specific context rather than hype (Clohessy \& Acton, 2019).

The business organisation must clearly understand and articulate the business problem that can be solved with BCT. The business case should be developed around the idea to increase business economic productivity and gaining sustainable performance Tracking return of investment is a business imperative. However, the success of the development, implementation and adoption, will depend not only on the business case, but collaborative and coordinated efforts from the all the stakeholders who are going to use and adopt the system (Dubey et al., 2020).

Therefore, before BCT adoption, business process analysis should be conducted, which will require mapping the existing risk management process and decision flows within the organisation, followed by developing a blueprint which will clearly identify the changes within the existing flows, as a result of the implementation (Alkhudary et al., 2020). The blueprint will help the managers and key decision makers to understand how deployment of 
the BCT solution will change the workflow, communication, structure within the departments and supply chain ecosystem, and to develop a cost-benefit-impact analysis map of the value captured by implementing the solution (Di Vaio \& Varriale, 2020).

Prioritization of BCT adoption should follow the business process analysis and will depend on the outcome of the cost-benefit-analysis, to determine and finalize the key objectives which will facilitate delivering the business goals and enhance the productivity at both the employee and inter as well as intra organisation levels. The prioritization method should consider the importance of the objective, effort required to deliver it, and the impact of the outcome. This is a key step to lead and drive BCT strategy because it considers the immediate short-term goals, medium term and long-term goals, from the inception, and therefore helps to build an BCT roadmap for the organisations (Cole et al., 2019; Schmidt \& Wagner, 2019).

Once the roadmap is developed, the managers will need to decide on how the BCT adoption will impact the stakeholders in the supply chain ecosystem, which is yet to be considered in the strategy by conducting a formal assessment (Dutta et al., 2020). Therefore, we propose a decision framework, considering five dimensions to facilitate understanding the impact of BCT in the supply chain ecosystem. These dimensions are relevant for managing risks and also for other contexts, which will help to enhance business productivity and competitive performance in the market. The proposed framework is further discussed below and presented in Fig. 5.

\subsubsection{Information resilience}

BCT offers information resilience through safe, secure and efficient information sharing between various entities (stakeholders) in the blockchain network (Behnke \& Janssen, 2020; Hastig \& Sodhi, 2020; Min, 2019). Therefore, the factors influencing this dimension in the decision framework are presented in the Table 6.

\subsubsection{Information management}

BCT offers an automated mechanism that facilitates managing information within a network (shared virtual space) in a seamless manner (Esmaeilian et al., 2020; Kshetri, 2018), and the factors pertaining to this dimension are further discussed in Table 7.

\subsubsection{Supply chain relationships}

BCT offers a trust less secure, decentralised and distributed virtual shared space, which facilitates both information sharing and transaction, eliminating the need for intermediaries $\left(3^{\text {rd }}\right.$ party), therefore inherently depend on the nature of relationship between the various stakeholders (Saberi et al., 2019; Wambaet al., 2020a). The factors pertaining to this dimension are further discussed in Table 8 .

\subsubsection{Business logic}

BCT offers a mechanism that facilitates managing creating rules that govern the processes and transactions between the stakeholders, which can lead to reducing the transaction costs and decreasing the decision latency time (Karamchandani et al., 2020; Queiroz et al., 2019). The factors pertaining to this dimension are further discussed in Table 9. 


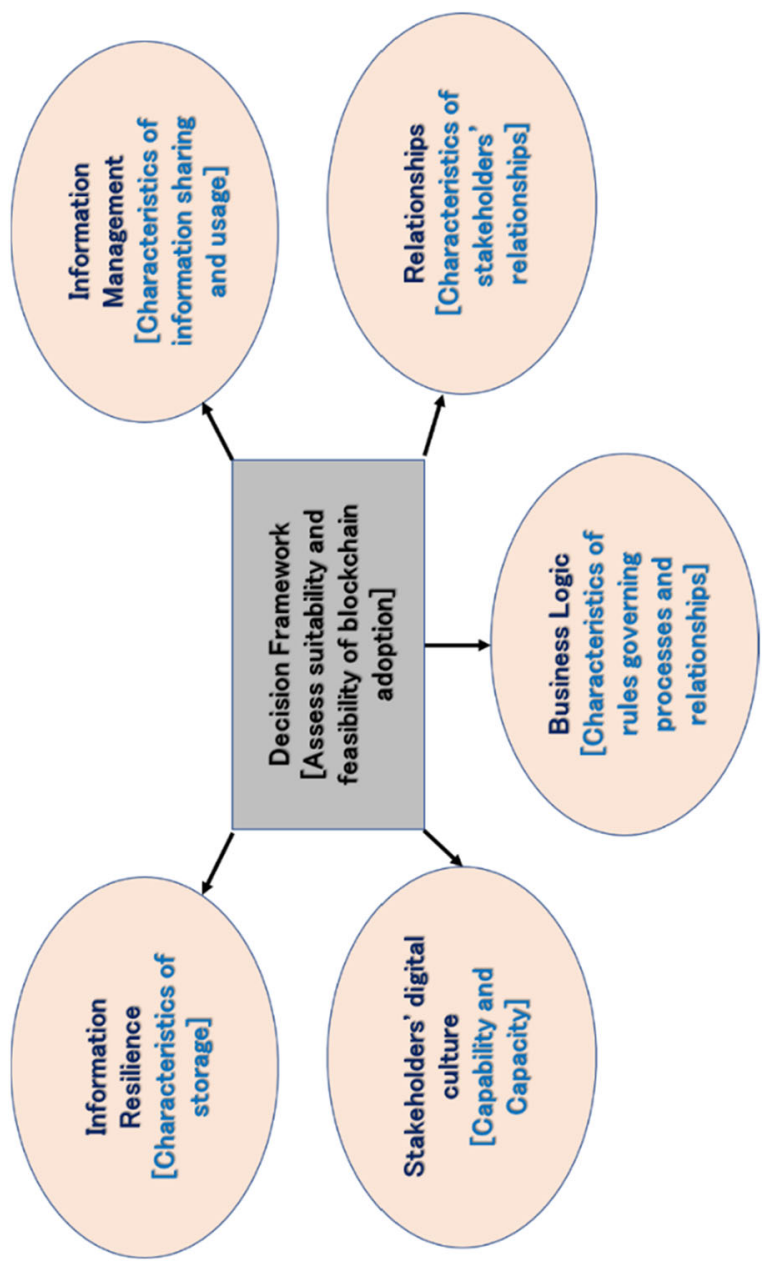

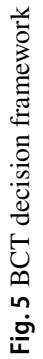


Table 6 Factors affecting information resilience

\begin{tabular}{|c|c|c|}
\hline Factors to consider & Yes & NO \\
\hline $\begin{array}{l}\text { Does the use-case/context } \\
\text { require information sharing } \\
\text { both at inter and intra } \\
\text { organisation levels? }\end{array}$ & \multirow{5}{*}{$\begin{array}{l}\text { If the answers to these questions are } \\
\text { YES, then BCT can offer value } \\
\text { and benefits for the organisation } \\
\text { in that use-case/context. } \\
\text { Therefore, BCT adoption seems } \\
\text { promising }\end{array}$} & \multirow[t]{5}{*}{$\begin{array}{l}\text { If the answers to one or more of } \\
\text { these questions is NO, then } \\
\text { BCT should be deemed } \\
\text { unsuitable for the given } \\
\text { use-case/context }\end{array}$} \\
\hline $\begin{array}{l}\text { Does the use-case/context } \\
\text { require persistent storage, } \\
\text { i.e., storing the state of the } \\
\text { current and historical } \\
\text { information? }\end{array}$ & & \\
\hline $\begin{array}{l}\text { Does the use-case/context } \\
\text { require efficient discovery of } \\
\text { information in real-time? }\end{array}$ & & \\
\hline $\begin{array}{l}\text { Does the use-case/context } \\
\text { require immutable and } \\
\text { unchangeable records of } \\
\text { information, to maintain } \\
\text { integrity of the stored data? }\end{array}$ & & \\
\hline $\begin{array}{l}\text { Does the use-case/context } \\
\text { require secure and safe } \\
\text { transmission of data, which } \\
\text { may or may not be business } \\
\text { critical? }\end{array}$ & & \\
\hline
\end{tabular}

Table 7 Factors affecting information management in a shared virtual pace

\begin{tabular}{|c|c|c|}
\hline Factors to consider & Yes & NO \\
\hline $\begin{array}{l}\text { Will the information be shared } \\
\text { with multiple parties } \\
\text { (stakeholders) in the supply } \\
\text { chain ecosystem? }\end{array}$ & \multirow{5}{*}{$\begin{array}{l}\text { If the answers to these questions } \\
\text { are YES, then BCT should be } \\
\text { adopted as it offers an automated } \\
\text { mechanism and protocol for } \\
\text { information management process } \\
\text { within the blockchain network }\end{array}$} & \multirow{5}{*}{$\begin{array}{l}\text { If the answers to any these } \\
\text { questions is NO, then BCT is } \\
\text { not suitable for use, and a } \\
\text { shared database can offer the } \\
\text { features necessary to } \\
\text { accomplish these tasks }\end{array}$} \\
\hline $\begin{array}{l}\text { Will multiple parties } \\
\text { (stakeholders) in the supply } \\
\text { chain ecosystem participate in } \\
\text { the data input process? }\end{array}$ & & \\
\hline $\begin{array}{l}\text { Will the information be updated } \\
\text { by multiple parties } \\
\text { (stakeholders) in the supply } \\
\text { chain ecosystem? }\end{array}$ & & \\
\hline $\begin{array}{l}\text { Will the information be audited by } \\
\text { multiple parties (stakeholders) } \\
\text { in the supply chain ecosystem? }\end{array}$ & & \\
\hline $\begin{array}{l}\text { Will the information validation } \\
\text { require consensus from multiple } \\
\text { parties (stakeholders) in the } \\
\text { supply chain ecosystem? }\end{array}$ & & \\
\hline
\end{tabular}


Table 8 Understanding relationships within the supply chain ecosystem in a shared virtual pace

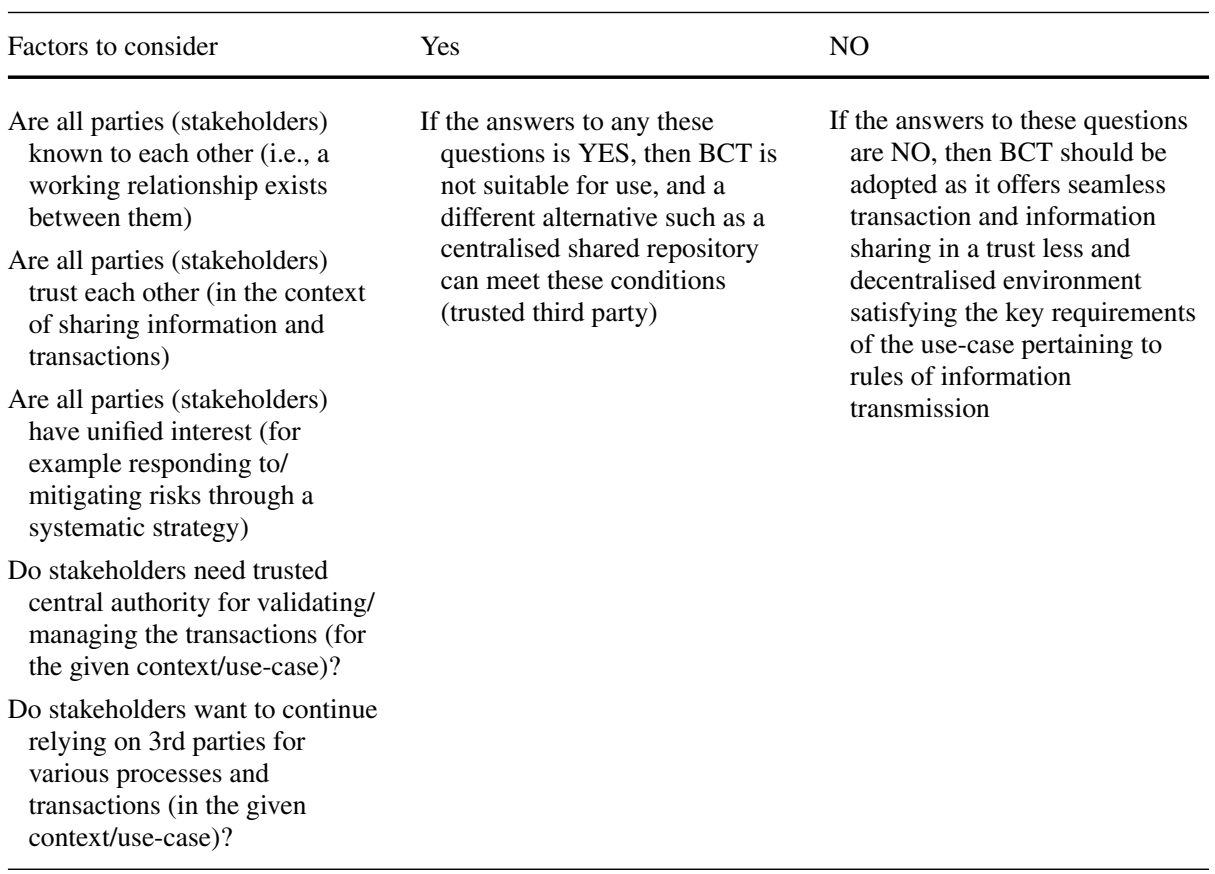

Table 9 Understanding the business logic governing the processes and transactions

\begin{tabular}{|c|c|c|}
\hline Factors to consider & YES & NO \\
\hline $\begin{array}{l}\text { Can the business processes and } \\
\text { transactions in the } \\
\text { use-case/context, represented by } \\
\text { conditional logic? } \\
\text { Can the business processes and } \\
\text { transactions in the } \\
\text { use-case/context, require a } \\
\text { standalone system, which } \\
\text { should be integrated with } \\
\text { existing infrastructure? }\end{array}$ & \multirow[t]{4}{*}{$\begin{array}{l}\text { If the answers to these questions } \\
\text { are YES, then BCT should be } \\
\text { adopted as it offers mechanisms } \\
\text { to write software logic that would } \\
\text { govern the processes, } \\
\text { transactions and their validation } \\
\text { automatically in a decentralised } \\
\text { virtual environment }\end{array}$} & \multirow[t]{4}{*}{$\begin{array}{l}\text { If the answers to any these } \\
\text { questions is NO, then BCT is } \\
\text { not suitable for use, and a } \\
\text { centralised share database } \\
\text { repository is required, where } \\
\text { rules governing the business } \\
\text { logic can be dynamically } \\
\text { updated and on a frequent } \\
\text { basis }\end{array}$} \\
\hline $\begin{array}{l}\text { Are the rules governing business } \\
\text { processes and transactions in } \\
\text { the use-case/context, more or } \\
\text { less static, i.e., does not change } \\
\text { regularly? }\end{array}$ & & \\
\hline $\begin{array}{l}\text { Does any stakeholder require } \\
\text { control over the rules governing } \\
\text { the business logic (i.e., rules are } \\
\text { not determined a single entity)? }\end{array}$ & & \\
\hline $\begin{array}{l}\text { Does the business process, logic } \\
\text { and rules involved managing } \\
\text { contractual agreements between } \\
\text { the stakeholders? }\end{array}$ & & \\
\hline
\end{tabular}


Table 10 Capacity and capabilities of the stakeholders in the context of digital readiness

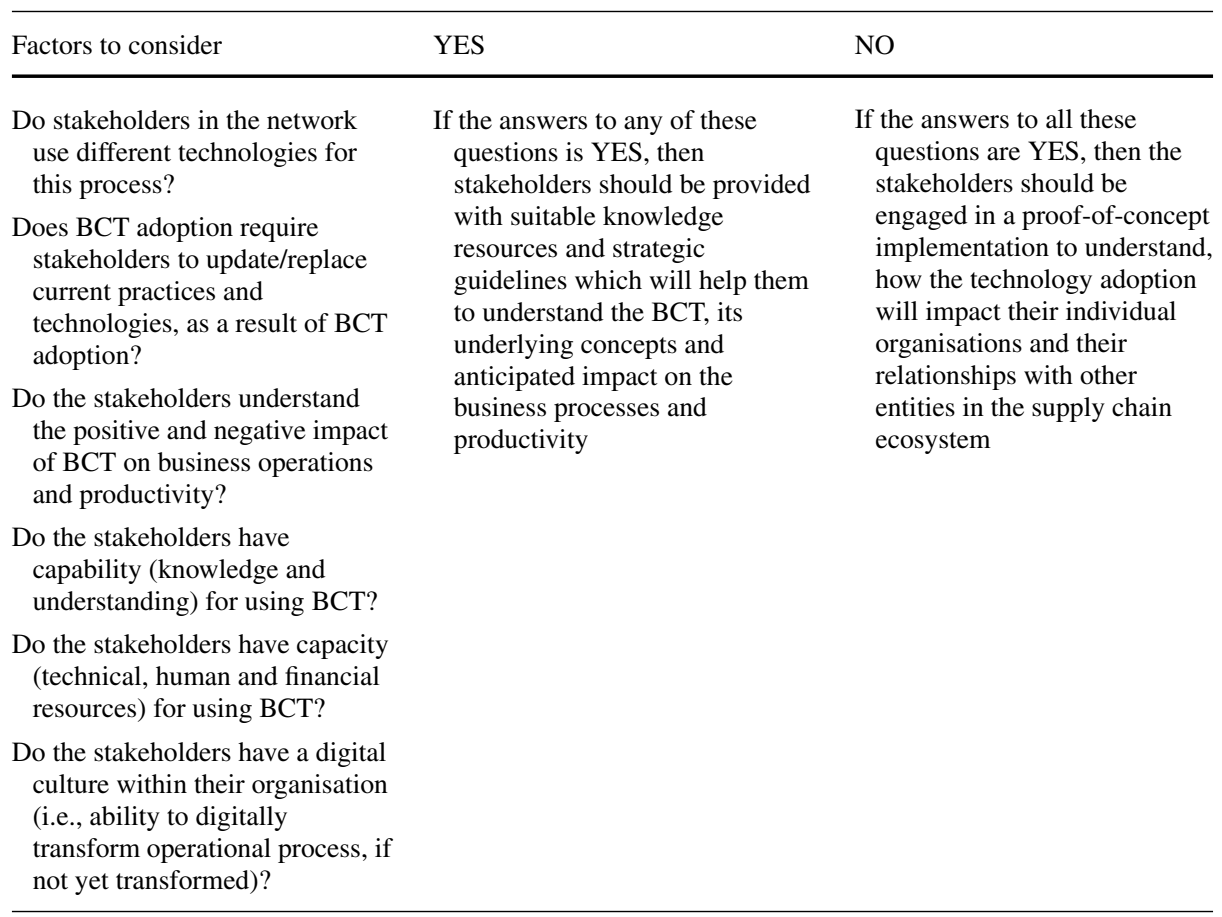

\subsubsection{Stakeholder digital culture}

BCT adoption will require mindset and culture within the organisations to embrace new technology and having the resources to engage in digital transformation, which is critical to achieve sustainable business performance and enhance dynamic capability within the competitive markets (Clohessy \& Acton, 2019; Tönnissen \& Teuteberg, 2020). The factors pertaining to this dimension are further discussed in Table 10.

\section{Research implications}

\subsection{Theoretical implications}

There is a growing interest on the potential of blockchain technology to support businesses. However, more evidence is needed about the specific value and factors affecting the adoption in core activities such as risk management, which is currently understudied (Wamba \& Queiroz, 2020). The role of the VUCA business environment in the adoption of BCT to manage risks to enhance sustainable performance and dynamic capabilities of business organisations is less discussed and understood in the current OSCM literature. Prior to this work, few studies have examined BCT adoption using technology acceptance models (Wong et al., 2020a; 2020b; Wamba et al., 2020b; Queiroz \& Wamba, 2019), but none of them focusing on the context of risk management. This research is advancing knowledge from a theoretical perspective in three ways, which are outline below. 
- Firstly, this is the first study reported in the OSCM literature that combines the VUCA and technology acceptance model to provide empirical insights on the adoption of BCT for risk management in complex business environment as a result of emergency and unexpected situations. Our study provides empirical evidence illustrating how context of using a technology can be integrated into TAM models to better understand the adoption behaviour in the context of employing BCT in risk management within organisations.

- Secondly, this study extends the BCT research in OSCM literature by opening a new avenue BCT adoption-risk management (Alkhudary et al., 2020; Choi et al., 2019) with a robust theoretical model. The results validating the model using the data captured from operations managers in the UK shows that organisations will use BCT to manage risks within the business processes stemming from the usefulness and ease of using the technology in that context. From a theoretical lens, this shows that constructs derived from TAM model can be used to predict the adoption of BCT for managing business risks in a VUCA business environment, thus showing the importance of purpose and context of using a technology in modelling its adoption behaviour among the stakeholders.

- Finally, the results obtained through validation of the proposed model brings new empirical insights showing the positive and significant relationship between resilience and adoption of blockchain for risk management. The findings suggest that resilient organisations would be prone to adopt blockchain for improving risk management. This is important because as $\mathrm{BCT}$ is continuing to be adopted by organisations and this adoption is further accelerated by digital transformation during COVID-19 pandemic and managers need to strategize their risk management practices within their organisations that will prevent disruptions and unintended business consequences caused by potential disruptions. Accordingly, managers will need better understanding and knowledge about BCT implementation for risk management to systematically reflect on the capabilities and limitations of the technology, which will help them to combine the risk management goals and priorities with BCT implementation in the uncertain and complex business environment, and supply chain ecosystem (Araz et al., 2020; Dolgui \& Ivanov, 2020; Manhart et al., 2020; Xu et al., 2020).

\subsection{Managerial implications}

The extant OSCM literature concerning BCT has highlighted the significance of how the adoption will require judicious integration of the technology with the existing business processes and collaboration with all stakeholders in the supply chain ecosystem. In this context, our study provides interesting empirical insights showing the potential of blockchain to deal with volatility, uncertainty, complexity, and ambiguity has a significant effect in the perceived usefulness and ease of use of blockchain in risk management, which will significantly and positively influence its adoption among the operations managers. Therefore, according to our findings supply chain practitioners can clearly see the value of blockchain considering risk management. The results also suggest that managers implementing blockchain must focus on making blockchain technology implementation user friendly, as pointed out by Kamble et al. (2018), and which will motivate the users to engage in the adoption of the technology. Our research finding have several implications for managers, which are discussed below.

- Firstly, BCT adoption for risk management within organisations will be facilitated by knowledge and understanding of the technology, which will facilitate organisations to realize value for the implementation (Dutta et al., 2020). Therefore, managers need to empower the employees within the organisation, partner organisation participating in the supply chain ecosystem with tools, resources and knowhow that will help to effectively 
integrate BCT within the risk management processes. Knowledge and capabilities will enable all participants within the supply chain ecosystem to not only understand the usefulness of technology but also make the implementation of BCT user-friendly and easy to adopt.

- Secondly, managers need to develop a culture of collaboration with multiple stakeholders within and outside the supply chain ecosystem such as trade partners, technology partners, government agencies, and regulators by developing a consortium (Clohessy \& Acton, 2019). This will create mechanisms to share and extend knowledge and build on that knowledge, to communicate, reflect and understand the impact of BCT on business processes considering the resources at hand. Such collaborative efforts will also facilitate making decisions pertaining to types of collaboration in the blockchain trust less environment, rules and protocols governing this collaboration, methods and ways to reach consensus in the blockchain environment, managing contractual relationships and technology platform selection which can be seamlessly integrated with the existing digital systems in the supply chain, which have been identified in our BCT decision framework.

- Thirdly, our BCT decision framework will help managers to assess the usefulness and feasibility of the technology in risk management and various other contexts, which will require continuous engagement with the stakeholders in the supply chain to understand the capabilities and opportunities offered by the technology. Our results show that the ease of using the technology will influence the adoption behaviour positively, therefore the engagement with stakeholders will help to establish the technical feasibility of BCT adoption both at inter and intra organisation levels. Understanding the technical feasibility will require assessing the digital readiness and develop a blueprint of existing risk management processes, capacity and capability of the trading partners (stakeholders), and how BCT adoption will impact the existing control mechanisms (risk response strategies), which has been outlined in our proposed BCT decision framework. These strategic initiatives are necessary to formulate realistic expectations from the BCT adoption, considering that both the technology implementation and adoption remains in an early phase of the software maturity lifecycle.

- Finally, BCT implementation will require a systematic approach to ensure the usefulness and ease of using the technology for managing risks and other business activities is clearly understood by other managers (stakeholder organisations) in the supply chain ecosystem (Bai et al., 2020; Carson et al., 2018). For example, business goals must be clearly mapped to the benefits offered by the technology and anticipated financial value, which could be demonstrated through a proof-of-concept project (very small-scale implementation). This will benefit the understanding and confidence of the stakeholders in the BCT usability and capability, compared to the existing processes. Then a pilot project implementation with a selection of stakeholders will help to provide a high-level assessment of the adoption and its impact on business processes and the organisations. The pilot project (small scale implementation) will help to understand how BCT adoption will transform business operations and the individual needs of stakeholders for achieving sustainable business performance across the organisations, and before end-end implementation (i.e., combining all stakeholders in the ecosystem). 


\section{Conclusion, limitations and future directions}

The exponential interest to adopt BCT in OSCM and lack of empirical insights in the current literature concerning BCT adoption to manage risks that will prevent disruptions in an uncertain and complex business environment are the motivation behind this study. This paper has provided an analysis of the value of VUCA and TAM for the adoption of blockchain in risk management. Data gathered from 116 practitioners has been analysed using structural equation modelling to investigate the relationships between the constructs in the proposed conceptual model. Findings suggest that the external context (VUCA) influences the individual managers' perception of usefulness and ease of using BCT for risk management. Results have also demonstrated that perception of usefulness and ease of using BCT and level of organisational resilience are significant drivers affecting the intention to use BCT for risk management.

The article is the first to empirically investigate the adoption of blockchain for risk management activities and introducing VUCA to account for the context surrounding this activity. Our work therefore provides an initial step for the researchers to understand how context and purpose of BCT implementation can impact the behavioural intention to adopt BCT, which will result in organisationally valued outcomes generating productivity and sustainable business performance, as a result of enhanced collaboration, cooperation and coordination among the stakeholders in the supply chain ecosystem. Evidence from other studies have indicated that organisations interested in implementing blockchain must consider the effect of the external context on the motivation of using the technology and invest in resources to facilitate the successful implementation of the technology (Janssen et al., 2020). Particularly, managers should be mindful of the importance of communicating the value of blockchain to support and enhance the efficacy of risk management activities at the same time as they plan the user-friendly and strategic implementation to avoid reluctance of using the new technology from the stakeholders (inter and intra organisation levels).

There are several avenues for future work addressing the limitations of the current study and further expand the BCT literature in OSCM, which are outlined below.

- Although we took precautions by employing suitable methods during the data sampling, collection and analysis to minimize the impacts of common method bias (CMB) and endogeneity (which are limitations of survey-based primary research) (Doty \& Glick, 1998), we argue that future research can design longitudinal studies drawing samples from more industries, countries, and informants with more diverse backgrounds to address the $\mathrm{CMB}$ and endogeneity effects. Once a model is validated using quantitative data, we suggest case-based research (Dobson, 2001) can be used to further test and validate the theoretical outcomes, examining BCT adoption through ethnographic studies (Myers, 1999), to provide more comprehensive insights. As this study is carried out with managers from the UK, the findings can be generalised to similar economies with the same degree of technical development and blockchain implementation. Further studies can test the applicability of the decision framework to countries with different characteristics and examine the applicability through cross-country studies.

- Secondly, the sample of our research may limit the generalizability of our results. Our model was tested in a developed economy, and we purposely chose to study the perspectives of operations managers is OSCM related context. Although purposive sampling and inclusion criteria employed in our study helped to enhance the internal validity of our empirical investigation, they often limit external ecological validity. We acknowledge that generalizability troubles all survey-based research (including ours), which can be addressed 
by conducting more empirical investigations across the world in different sectors, which will aid in comparing the empirical insights (further contributing to the research in this area) (Mann, 2003). However, while comparing and contrasting results emerging from different contexts, findings should be applied with caution to ensure ecological validity and reproducibility.

- We believe that including new constructs and corresponding variables to predict the direct and mediating effects influencing BCT adoption for risk management not only among managers but also at employees' level and its impact on firm performance and dynamic capability can further enrich our model and provide novel empirical insights for the managers and employees alike. Such variables include constructs drawn from the TAM model variants-performance expectancy, effort expectancy, technology affinity, social influence, institution theory (Dubey et al., 2019)—-market pressure, external influencers, regulations and government guidelines, management theories (Erjavec \& Trkman, 2020) — organisational culture, leadership, innovation, job satisfaction, and resource-based view (Shibin et al., 2020) — digital readiness, technology resources, and training resources, knowledge-based view (Kong et al., 2020) — tacit knowledge, explicit knowledge, knowledge creation and co-creation, and knowledge application (through pilot studies), all of this in the context of BCT adoption. This will further expand our model and allow researchers to explore the direct and indirect effects between constructs to provide total effects, which will open new avenues of research pertaining to risk and crisis management, therefore making a significant contribution to this emerging area in OSCM literature.

- Fourthly, our proposed BCT decision framework can be empirically tested using surveybased to understand the perspectives of managers, stakeholders within the supply chain ecosystem and technology partners of the organisations, to further refine the model. Furthermore, case-study research and longitudinal studies can help to provide interesting insights pertaining to the performance of the framework in the BCT industry implementation, which will help to further extend the framework with new dimensions considering advances and innovations in BCT implementation (i.e. large scale adoption and expansion, beyond pilot projects).

- Finally, blockchain is not a standalone technology. Introducing its link with other emerging technologies (such as artificial intelligence, big data analytics, cloud computing, digital twins) and assessing their impact on risk management will be valuable to capture deeper understanding of the potential benefits of implementing these emerging technologies (Araz et al., 2020). Such studies will gather evidence and provide novel insights pertaining to the impact of digitalisation and digital transformation (combining use of multiple technologies) for risk management in OSCM, where notion of autonomous supply chain and smart factories have started to gain momentum, both in the developed and developing economies.

\section{Appendix}

See Table 11. 
Table 11 Survey Instrument

\begin{tabular}{|c|c|c|}
\hline Construct & Latent Variables (Items) & References \\
\hline VUCA Environment & $\begin{array}{l}\text { Blockchain technology would } \\
\text { help minimize volatility caused } \\
\text { by risk dynamics and velocity } \\
\text { - Blockchain technology would } \\
\text { help minimize uncertainty (i.e. } \\
\text { lack of information and } \\
\text { contextual awareness) } \\
\text { - Blockchain technology would } \\
\text { help minimize complexity due to } \\
\text { vast and variable information } \\
\text { - Blockchain technology would } \\
\text { help minimize ambiguity (i.e. } \\
\text { confusion, subjective judgement } \\
\text { and strategic misalignment) }\end{array}$ & $\begin{array}{l}\text { Baran and Woznyj (2020), Bennett } \\
\text { and Lemoine (2014) }\end{array}$ \\
\hline $\begin{array}{l}\text { Perceived Usefulness of } \\
\text { BCT }\end{array}$ & $\begin{array}{l}\text { Using blockchain technology } \\
\text { would: } \\
\text { - Facilitate tracing and tracking } \\
\text { information related to processes } \\
\text { for risk management } \\
\text { - Allow us to perform secure } \\
\text { transactions for risk management } \\
\text { - Allow us to effectively } \\
\text { communicate with customers and } \\
\text { suppliers to manage risks } \\
\text { - Enhance information quality and } \\
\text { reliability for risk management } \\
\text { - Facilitate swifter data-driven } \\
\text { decision-making for risk } \\
\text { management }\end{array}$ & $\begin{array}{l}\text { Wamba and Queiroz (2020), Wong } \\
\text { et al. (2020a, 2020b), Lederer } \\
\text { et al. (2000), Szajna (1996) }\end{array}$ \\
\hline $\begin{array}{l}\text { Perceived ease of using } \\
\text { BCT }\end{array}$ & $\begin{array}{l}\text { - I would find it easy to get } \\
\text { blockchain technology to do what } \\
\text { I need to do for risk management } \\
\text { - I think the technology is easy and } \\
\text { understandable } \\
\text { - It would be easy for me to } \\
\text { become skilful at using the } \\
\text { technology for risk management } \\
\text { - I think integrating the technology } \\
\text { will be fairly easy compared to } \\
\text { conventional practices used for } \\
\text { risk management }\end{array}$ & $\begin{array}{l}\text { Wamba and Queiroz (2020), Wong } \\
\text { et al. (2020a, 2020b), Lederer } \\
\text { et al. (2000), Szajna (1996) }\end{array}$ \\
\hline Resilience & $\begin{array}{l}\text { We are able to cope with changes } \\
\text { brought by disruptions/ } \\
\text { emergency situations }\end{array}$ & $\begin{array}{l}\text { Dubey et al. (2020), Cole et al. } \\
\text { (2019), Min (2019), Queiroz et al. } \\
\text { (2019) }\end{array}$ \\
\hline
\end{tabular}


Table 11 (continued)

\begin{tabular}{|c|c|c|}
\hline Construct & Latent Variables (Items) & References \\
\hline Intention to adopt & $\begin{array}{l}\text { - We are able to adapt to the } \\
\text { disruption easily } \\
\text { - We are able to provide a quick } \\
\text { response to disruptions } \\
\text { - We are able to maintain high } \\
\text { situational awareness at all times } \\
\text { - I predict my organisation will } \\
\text { adopt blockchain technology for } \\
\text { risk management in the future } \\
\text { - I plan to integrate blockchain } \\
\text { technology for risk management } \\
\text { in the near future } \\
\text { - I expect that my organisation will } \\
\text { integrate blockchain technology } \\
\text { to enhance risk management in } \\
\text { the future } \\
\text { - My organisation plans to digitally } \\
\text { transform risk management } \\
\text { operations through integrating } \\
\text { blockchain technology }\end{array}$ & $\begin{array}{l}\text { Wang et al. (2020), Wong et al. } \\
\text { (2020a, 2020b), Lederer et al. } \\
\text { (2000), Szajna (1996) }\end{array}$ \\
\hline
\end{tabular}

\section{References}

Akter, S., Michael, K., Uddin, M. R., McCarthy, G., \& Rahman, M. (2020). Transforming business using digital innovations: the application of AI, blockchain, cloud and data analytics. Annals of Operations Research, 1-33.

Albayati, H., Kim, S. K., \& Rho, J. J. (2020). Accepting financial transactions using blockchain technology and cryptocurrency: A customer perspective approach. Technology in Society, 62, 101320.

Alkhudary, R., Brusset, X., \& Fenies, P. (2020). Blockchain and risk in supply chain management. In International conference on dynamics in logistics (pp. 159-165). Springer.

Ambulkar, S., Blackhurst, J., \& Grawe, S. (2015). Firm's resilience to supply chain disruptions: Scale development and empirical examination. Journal of Operations Management, 33, 111-122.

Angelis, J., \& da Silva, E. R. (2019). Blockchain adoption: A value driver perspective. Business Horizons, 62(3), 307-314.

Araz, O. M., Choi, T. M., Olson, D., \& Salman, F. S. (2020). Data analytics for operational risk management. Decision Sciences, 51(6), 1316-1319.

Babich, V., \& Hilary, G. (2020). OM Forum—distributed ledgers and operations: What operations management researchers should know about blockchain technology. Manufacturing \&amp; Service Operations Management, 22(2), 223-240.

Bai, C. A., Cordeiro, J., \& Sarkis, J. (2020). Blockchain technology: Business, strategy, the environment, and sustainability. Business Strategy and the Environment, 29(1), 321-322.

Baker, J. (2012). The technology-organization-environment framework. Information systems theory, pp. $231-245$.

Balasubramanian, S., Shukla, V., Sethi, J. S., Islam, N., \& Saloum, R. (2021). A readiness assessment framework for blockchain adoption: A healthcare case study. Technological Forecasting and Social Change, $165,120536$.

Baran, B. E., \& Woznyj, H. M. (2020). Managing VUCA: The human dynamics of agility. Organizational Dynamics.

Behnke, K., \& Janssen, M. F. W. H. A. (2020). Boundary conditions for traceability in food supply chains using blockchain technology. International Journal of Information Management, 52, 101969.

Bennett, N., \& Lemoine, J. (2014). What VUCA really means for you. Harvard Business Review, 92(1/2). 
Bodkhe, U., Tanwar, S., Parekh, K., Khanpara, P., Tyagi, S., Kumar, N., \& Alazab, M. (2020). Blockchain for industry 4.0: A comprehensive review. IEEE Access, 8, 79764-79800.

Burnard, K., \& Bhamra, R. (2011). Organisational resilience: Development of a conceptual framework for organisational responses. International Journal of Production Research., 49(18), 5581-5599.

Cao, M., Vonderembse, M. A., Zhang, Q., \& Ragu-Nathan, T. S. (2010). Supply chain collaboration: Conceptualisation and instrument development. International Journal of Production Research, 48(22), 6613-6635.

Carson, B., Romanelli, G., Walsh, P., \& Zhumaev, A. (2018). Blockchain beyond the hype: What is the strategic business value. McKinsey \& Company, 1-13.

Chelst, K., \& Bodily, S. E. (2000). Structured risk management: Filling a gap in decision analysis education. Journal of the Operational Research Society, 51, 1420-1432.

Choi, T. M., Wen, X., Sun, X., \& Chung, S. H. (2019). The mean-variance approach for global supply chain risk analysis with air logistics in the blockchain technology era. Transportation Research Part E: Logistics and Transportation Review, 127, 178-191.

Clohessy, T., \& Acton, T. (2019). Investigating the influence of organizational factors on blockchain adoption. Industrial Management \& Data Systems.

Clohessy, T., Treiblmaier, H., Acton, T., \& Rogers, N. (2020). Antecedents of blockchain adoption: An integrative framework. Strategic Change, 29(5), 501-515.

Cole, R., Stevenson, M., \& Aitken, J. (2019). Blockchain technology: Implications for operations and supply chain management. Supply Chain Management: An International Journal, 24(4), 469-483.

Covello, V. T. (1987). Decision analysis and risk management decision making: Issues and methods. Risk Analysis, 7, 131-139.

Dadeliene, R., Dadelo, S., Pozniak, N., \& Sakalauskas, L. (2020). Analysis of top kayakers' training-intensity distribution and physiological adaptation based on structural modelling. Annals of Operations Research, $1-16$.

Dashottar, S., \& Srivastava, V. (2021). Corporate banking_risk management, regulatory and reporting framework in India: A Blockchain application-based approach. Journal of Banking Regulation, 22, 39-51.

Davis, F. D. (1989). Perceived usefulness, perceived ease of use, and user acceptance of information technology. MIS Quarterly, 319-340

de Sá, M. M., de Souza Miguel, P. L., de Brito, R. P., \& Pereira, S. C. F. (2019). Supply chain resilience: the whole is not the sum of the parts. International Journal of Operations \& Production Management.

Di Vaio, A., \& Varriale, L. (2020). Blockchain technology in supply chain management for sustainable performance: Evidence from the airport industry. International Journal of Information Management, 52, 102014.

Dobson, P. J. (2001). Longitudinal case research: A critical realist perspective. Systemic Practice and Action Research, 14(3), 283-296.

Dolgui, A., \& Ivanov, D. (2020). Exploring supply chain structural dynamics: New disruptive technologies and disruption risks. International Journal of Production Economics.

Doll, W. J., Xia, W., \& Torkzadeh, G. (1994). A confirmatory factor analysis of the end-user computing satisfaction instrument. MIS Quarterly, 453-461.

Doty, D. H., \& Glick, W. H. (1998). Common methods bias: Does common methods variance really bias results? Organizational Research Methods, 1(4), 374-406.

Dubey, R., Gunasekaran, A., Childe, S. J., Blome, C., \& Papadopoulos, T. (2019). Big data and predictive analytics and manufacturing performance: Integrating institutional theory, resource-based view and big data culture. British Journal of Management, 30(2), 341-361.

Dubey, R., Gunasekaran, A., Bryde, D.J., Dwivedi, Y.K. \& Papadopoulos, T. (2020). Blockchain technology for enhancing swift-trust, collaboration and resilience within a humanitarian supply chain setting. International Journal of Production Research, 58(11), 3381-3398.

Dufour, É., Laporte, G., Paquette, J., \& Rancourt, M. È. (2018). Logistics service network design for humanitarian response in East Africa. Omega, 74, 1-14.

Dutta, P., Choi, T. M., Somani, S., \& Butala, R. (2020). Blockchain technology in supply chain operations: Applications, challenges and research opportunities. Transportation Research Part E: Logistics and Transportation Review, 142, 102067.

Erjavec, J., \& Trkman, P. (2020). Behavioural operations management-identification of its research program. International Journal of Services and Operations Management, 36(1), 42-71.

Esmaeilian, B., Sarkis, J., Lewis, K., \& Behdad, S. (2020). Blockchain for the future of sustainable supply chain management in Industry 4.0. Resources, Conservation and Recycling, 163, 105064.

Felin, T., \& Lakhani, K. (2018). What problems will you solve with blockchain? MIT Sloan Management Review, 60(1), 32-38.

Gartner Forecast (2019) Blockchain business value, worldwide, 2017-2030. Last accessed: 26/12/2020. https:// www.gartner.com/en/documents/3627117/forecast-blockchain-business-value-worldwide-2017-2030 
Gejke, C. (2018). A new season in the risk landscape: Connecting the advancement in technology with changes in customer behaviour to enhance the way risk is measured and managed. Journal of Risk Management in Financial Institutions, 11, 148-155.

Gölzer, P., \& Fritzsche, A. (2017). Data-driven operations management: Organisational implications of the digital transformation in industrial practice. Production Planning \&amp; Control, 28(16), 1332-1343.

Green, J.L., Camilli, G., \& Elmore, P. B. eds. (2012). Handbook of complementary methods in education research. Routledge.

Grover, P., Kar, A. K., \& Dwivedi, Y. K. (2020). Understanding artificial intelligence adoption in operations management: insights from the review of academic literature and social media discussions. Annals of Operations Research, 1-37.

Gurtu, A., \& Johny, J. (2019). Potential of blockchain technology in supply chain management: A literature review. International Journal of Physical Distribution \& Logistics Management.

Hair, J. F., Black, W. C., Babin, B. J., \& Anderson, R. E. (2013). Multivariate data analysis. Pearson Education Limited.

Hastig, G. M., \& Sodhi, M. S. (2020). Blockchain for supply chain traceability: Business requirements and critical success factors. Production and Operations Management, 29(4), 935-954.

Holden, W., \& Moar, J. (2017). Blockchain enterprise survey: Deployments, benefits \& attitudes. Juniper Research.

Hughes, L., Dwivedi, Y. K., Misra, S. K., Rana, N. P., Raghavan, V., \& Akella, V. (2019). Blockchain research, practice and policy: Applications, benefits, limitations, emerging research themes and research agenda. International Journal of Information Management, 49, 114-129.

Ivanov, D., \& Dolgui, A. (2020). Viability of intertwined supply networks: Extending the supply chain resilience angles towards survivability. A position paper motivated by COVID-19 outbreak. International Journal of Production Research, 58(10), 2904-2915.

Ivanov, D., Dolgui, A., \& Sokolov, B. (2019). The impact of digital technology and Industry 4.0 on the ripple effect and supply chain risk analytics. International Journal of Production Research, 57, 829-846.

Janssen, M., Weerakkody, V., Ismagilova, E., Sivarajah, U., \& Irani, Z. (2020). A framework for analysing blockchain technology adoption: Integrating institutional, market and technical factors. International Journal of Information Management, 50, 302-309.

Jüttner, U. (2005). Supply chain risk management. The International Journal of Logistics Management.

Kalapouti, K., Petridis, K., Malesios, C., \& Dey, P. K. (2017). Measuring efficiency of innovation using combined data envelopment analysis and structural equation modeling: empirical study in EU regions. Annals of Operations Research, 1-24.

Kamble, S., Gunasekaran, A., \& Arha, H. (2018). Understanding the Blockchain technology adoption in supply chains-Indian context. International Journal of Production Research, 1-25.

Kamble, S. S., Gunasekaran, A., Kumar, V., Belhadi, A., \& Foropon, C. (2020). A machine learning based approach for predicting blockchain adoption in supply Chain. Technological Forecasting and Social Change, 120465.

Karamchandani, A., Srivastava, S. K., \& Srivastava, R. K. (2020). Perception-based model for analyzing the impact of enterprise blockchain adoption on SCM in the Indian service industry. International Journal of Information Management, 52, 102019.

Khan, M., Imtiaz, S., Parvaiz, G. S., Hussain, A., \& Bae, J. (2021). Integration of internet-of-things with blockchain technology to enhance humanitarian logistics performance. IEEE Access, 9, 25422-25436.

Khayer, A., Bao, Y., \& Nguyen, B. (2020a). Understanding cloud computing success and its impact on firm performance: an integrated approach. Industrial Management \& Data Systems.

Khayer, A., Talukder, M. S., Bao, Y., \& Hossain, M. N. (2020b). Cloud computing adoption and its impact on SMEs' performance for cloud supported operations: A dual-stage analytical approach. Technology in Society, 60, 101225.

Kodym, O., Kubáč, L., \& Kavka, L. (2020). Risks associated with Logistics 4.0 and their minimization using blockchain. Open Engineering, 10, 74-85.

Kong, T., Feng, T., Huang, Y., \& Cai, J. (2020). How to convert green supply chain integration efforts into green innovation: A perspective of knowledge-based view. Sustainable Development.

Koppenjan, J., \& Groenewegen, J. (2005). Institutional design for complex technological systems. International Journal of Technology, Policy and Management, 5(3), 240-257.

Kouhizadeh, M., Saberi, S., \& Sarkis, J. (2020). Blockchain technology and the sustainable supply chain: Theoretically exploring adoption barriers. International Journal of Production Economics, 231, 107831.

Kshetri, N. (2018). 1 Blockchain's roles in meeting key supply chain management objectives. International Journal of Information Management, 39, 80-89.

Langley, P. (2018). Information or Evidence? Abandoning imaginary worlds for blockchains in health technology assessment. Innovations in Pharmacy, 9(3), 12-12. 
Lederer, A. L., Maupin, D. J., Sena, M. P., \& Zhuang, Y. (2000). The technology acceptance model and the World Wide Web. Decision Support Systems, 29(3), 269-282.

Lohmer, J., Bugert, N., \& Lasch, R. (2020). Analysis of resilience strategies and ripple effect in blockchaincoordinated supply chains: An agent-based simulation study. International Journal of Production Economics.

Lohmer, J. (2019). Applicability of blockchain technology in scheduling resources within distributed manufacturing. In Logistics management (pp. 89-103). Springer.

Macdonald, J. R., Zobel, C. W., Melnyk, S. A., \& Griffis, S. E. (2018). Supply chain risk and resilience: Theory building through structured experiments and simulation. International Journal of Production Research, 56(12), 4337-4355.

Malesios, C., Dey, P. K., \& Abdelaziz, F. B. (2018). Supply chain sustainability performance measurement of small and medium sized enterprises using structural equation modeling. Annals of Operations Research, $1-31$.

Malyavkina, L. I., Savina, A. G., \& Parshutina, I. G. (2019). Blockchain technology as the basis for digital transformation of the supply chain management system: benefits and implementation challenges. In $1 s t$ International scientific conference" modern management trends and the digital economy: From regional development to global economic growth" (MTDE 2019). Atlantis Press

Manhart, P., Summers, J. K., \& Blackhurst, J. (2020). A meta-analytic review of supply chain risk management: Assessing buffering and bridging strategies and firm performance. Journal of Supply Chain Management.

Mann, C.J. (2003). Observational research methods. Research design II: cohort, cross sectional, and casecontrol studies. Emergency Medicine Journal, 20(1), 54-60.

Melnyk, S. A., Closs, D. J., Griffis, S. E., Zobel, C. W., \& Macdonald, J. R. (2014). Understanding supply chain resilience. Supply Chain Management Review, 18(1), 34-41.

Millar, C. C., Groth, O., \& Mahon, J. F. (2018). Management innovation in a VUCA World: Challenges and recommendations. California Management Review, 61(1), 5-14.

Min, H. (2019). Blockchain technology for enhancing supply chain resilience. Business Horizons, 62(1), 35-45.

Montecchi, M., Plangger, K., \& Etter, M. (2019). It's real, trust me! Establishing supply chain provenance using blockchain. Business Horizons, 62, 283-293.

Munir, M., Jajja, M. S. S., Chatha, K. A., \& Farooq, S. (2020). Supply chain risk management and operational performance: The enabling role of supply chain integration. International Journal of Production Economics, 227, 107667.

Myers, M. D. (1999). Investigating information systems with ethnographic research. Communications of the Association for Information Systems, 2(1), 23.

Newman, J. P., Maier, H. R., Riddell, G. A., Zecchin, A. C., Daniell, J. E., Schaefer, A. M., van Delden, H., Khazai, B., O’Flaherty, M. J., \& Newland, C. P. (2017). Review of literature on decision support systems for natural hazard risk reduction: Current status and future research directions. Environmental Modelling \& Software, 96, 378-409.

Nuryyev, G., Wang, Y. P., Achyldurdyyeva, J., Jaw, B. S., Yeh, Y. S., Lin, H. T., \& Wu, L. F. (2020). Blockchain technology adoption behavior and sustainability of the business in tourism and hospitality SMEs: An empirical study. Sustainability, 12(3), 1256.

Orji, I. J., Kusi-Sarpong, S., Huang, S., \& Vazquez-Brust, D. (2020). Evaluating the factors that influence blockchain adoption in the freight logistics industry. Transportation Research Part E: Logistics and Transportation Review, 141, 102025.

Pillai, R., \& Sivathanu, B. (2020). Adoption of artificial intelligence (AI) for talent acquisition in IT/ITeS organizations. Benchmarking: An International Journal.

Podsakoff, P. M., MacKenzie, S. B., Lee, J. Y., \& Podsakoff, N. P. (2003). Common method biases in behavioral research: A critical review of the literature and recommended remedies. Journal of Applied Psychology, $88(5), 879$.

Polyviou, M., Croxton, K. L., \& Knemeyer, A. M. (2019). Resilience of medium-sized firms to supply chain disruptions: the role of internal social capital. International Journal of Operations \& Production Management.

Pournader, M., Shi, Y., Seuring, S., \& Koh, S. L. (2020). Blockchain applications in supply chains, transport and logistics: A systematic review of the literature. International Journal of Production Research, 58(7), 2063-2081.

Queiroz, M. M., Telles, R., \& Bonilla, S. H. (2019). Blockchain and supply chain management integration: A systematic review of the literature. Supply Chain Management: An International Journal.

Queiroz, M. M., \& Wamba, S. F. (2019). Blockchain adoption challenges in supply chain: An empirical investigation of the main drivers in India and the USA. International Journal of Information Management, 46, 70-82. 
Queiroz, M. M., Fosso Wamba, S., De Bourmont, M., \& Telles, R. (2020). Blockchain adoption in operations and supply chain management: empirical evidence from an emerging economy. International Journal of Production Research, 1-17.

Riesco, R., Larriva-Novo, X., \& Villagra, V. A. (2020). Cybersecurity threat intelligence knowledge exchange based on blockchain. Telecommunication Systems, 73, 259-288.

Ritchie, B., \& Brindley, C. (2007). An emergent framework for supply chain risk management and performance measurement. Journal of the Operational Research Society, 58, 1398-1411.

Rodríguez-Espíndola, O., Alem, D., \& Pelegrin Da Silva, L. (2020a). A shortage risk mitigation model for multi-agency coordination in logistics planning. Computers \& Industrial Engineering, 148, 106676

Rodríguez-Espíndola, O., Chowdhury, S., Beltagui, A., \& Albores, P. (2020b). The potential of emergent disruptive technologies for humanitarian supply chains: the integration of blockchain, Artificial Intelligence and 3D printing. International Journal of Production Research, 1-21.

Rogers, E. M. (2010). Diffusion of innovations. Simon and Schuster.

Romero-Silva, R., \& de Leeuw, S. (2021). Learning from the past to shape the future: A comprehensive text mining analysis of OR/MS reviews. Omega, 100, 102388

Rubbio, I., Bruccoleri, M., Pietrosi, A., \& Ragonese, B. (2019). Digital health technology enhances resilient behaviour: evidence from the ward. International Journal of Operations \& Production Management.

Saberi, S., Kouhizadeh, M., Sarkis, J., \& Shen, L. (2019). Blockchain technology and its relationships to sustainable supply chain management. International Journal of Production Research, 57(7), 2117-2135.

Saunders, M. N. K., Lewis, P., \& Thornhill, A. (2015). Research methods for business students. Pearson Education Limited.

Schmidt, C. G., \& Wagner, S. M. (2019). Blockchain and supply chain relations: A transaction cost theory perspective. Journal of Purchasing and Supply Management, 25(4), 100552.

Scholten, K., \& Schilder, S. (2015). The role of collaboration in supply chain resilience. Supply Chain Management: An International Journal.

Scholten, K., Sharkey Scott, P., \& Fynes, B. (2019). Building routines for non-routine events: Supply chain resilience learning mechanisms and their antecedents. Supply Chain Management: An International Journal, 24, 430-442.

Sheffi, Y. (2007). The resilient enterprise: Overcoming vulnerability for competitive advantage. Zone Books.

Shibin, K. T., Dubey, R., Gunasekaran, A., Hazen, B., Roubaud, D., Gupta, S., \& Foropon, C. (2020). Examining sustainable supply chain management of SMEs using resource based view and institutional theory. Annals of Operations Research, 290(1), 301-326.

Sideridis, G., Simos, P., Papanicolaou, A., \& Fletcher, J. (2014). Using structural equation modeling to assess functional connectivity in the brain: Power and sample size considerations. Educational and Psychological Measurement, 74(5), 733-758.

Singh, S., Sharma, P. K., Yoon, B., Shojafar, M., Cho, G. H., \& Ra, I. H. (2020). Convergence of blockchain and artificial intelligence in IoT network for the sustainable smart city. Sustainable Cities and Society, 63, 102364.

Sternberg, H. S., Hofmann, E., \& Roeck, D. (2020). The struggle is real: Insights from a supply chain blockchain case. Journal of Business Logistics.

Stevenson, M., \& Busby, J. (2015). An exploratory analysis of counterfeiting strategies. International Journal of Operations \& Production Management.

Szajna, B. (1996). Empirical evaluation of the revised technology acceptance model. Management Science, 42(1), 85-92.

Tang, C. S. (2006). Perspectives in supply chain risk management. International Journal of Production Economics, 103(2), 451-488.

Tönnissen, S., \& Teuteberg, F. (2020). Analysing the impact of blockchain-technology for operations and supply chain management: An explanatory model drawn from multiple case studies. International Journal of Information Management, 52, 101953.

Toufaily, E., Zalan, T., \& Dhaou, S. B. (2021). A framework of blockchain technology adoption: An investigation of challenges and expected value. Information \& Management, 58(3), 103444.

Tsolakis, N., Niedenzu, D., Simonetto, M., Dora, M., \& Kumar, M. (2020). Supply network design to address United Nations sustainable development goals: A case study of blockchain implementation in Thai fish industry. Journal of Business Research.

van Dorp, J. R. (2005). Statistical dependence through common risk factors: With applications in uncertainty analysis. European Journal of Operational Research, 161, 240-255.

Venkatesh, V., Thong, J. Y., \& Xu, X. (2016). Unified theory of acceptance and use of technology: A synthesis and the road ahead. Journal of the Association for Information Systems, 17(5), 328-376. 
Venkatesh, V., Thong, J. Y., Chan, F. K., Hu, P. J. H., \& Brown, S. A. (2011). Extending the two-stage information systems continuance model: Incorporating UTAUT predictors and the role of context. Information Systems Journal, 21(6), 527-555.

Verma, S., Bhattacharyya, S. S., \& Kumar, S. (2018). An extension of the technology acceptance model in the big data analytics system implementation environment. Information Processing \&amp; Management, 54(5), 791-806.

Wamba, S. F., \& Queiroz, M. M. (2020). Blockchain in the operations and supply chain management: Benefits, challenges and future research opportunities.

Wamba, S. F., Kala Kamdjoug, J. R., Epie Bawack, R., \& Keogh, J. G. (2020a). Bitcoin, blockchain and fintech: A systematic review and case studies in the supply chain. Production Planning \&amp; Control, 31(2-3), 115-142.

Wamba, S. F., Queiroz, M. M., \& Trinchera, L. (2020b). Dynamics between blockchain adoption determinants and supply chain performance: An empirical investigation. International Journal of Production Economics, 107791.

Wang, K., Yan, X., \& Fu, K. (2020). Research on risk management of agricultural products supply chain based on blockchain technology. Open Journal of Business and Management, 8(6), 2493-2503.

Wang, Y., Han, J. H., \& Beynon-Davies, P. (2019). Understanding blockchain technology for future supply chains: a systematic literature review and research agenda. Supply Chain Management: An International Journal.

Wolf, E. J., Harrington, K. M., Clark, S. L., \& Miller, M. W. (2013). Sample size requirements for structural equation models: An evaluation of power, bias, and solution propriety. Educational and Psychological Measurement, 73(6), 913-934.

Wong, L. W., Leong, L. Y., Hew, J. J., Tan, G. W. H., \& Ooi, K. B. (2020b). Time to seize the digital evolution: Adoption of blockchain in operations and supply chain management among Malaysian SMEs. International Journal of Information Management, 52, 101997.

Wong, L. W., Tan, G. W. H., Lee, V. H., Ooi, K. B., \& Sohal, A. (2020a). Unearthing the determinants of blockchain adoption in supply chain management. International Journal of Production Research, 58(7), 2100-2123.

Worley, C. G., \& Jules, C. (2020). COVID-19's uncomfortable revelations about agile and sustainable organizations in a VUCA world. The Journal of Applied Behavioral Science, 56(3), 279-283.

Xu, S., Zhang, X., Feng, L., \& Yang, W. (2020). Disruption risks in supply chain management: A literature review based on bibliometric analysis. International Journal of Production Research, 58(11), 3508-3526.

Yadav, V. S., Singh, A. R., Raut, R. D., \& Govindarajan, U. H. (2020). Blockchain technology adoption barriers in the Indian agricultural supply chain: an integrated approach. Resources, Conservation and Recycling, 161, 104877.

Ying, W., Jia, S., \& Du, W. (2018). Digital enablement of blockchain: Evidence from HNA group. International Journal of Information Management, 39, 1-4.

Zigurs, I., \& Buckland, B. K. (1998). A theory of task/technology fit and group support systems effectiveness. MIS Quarterly, 313-334.

Zwitter, A., \& Boisse-Despiaux, M. (2018). Blockchain for humanitarian action and development aid. Journal of International Humanitarian Action, 3(1), 1-7.

Publisher's Note Springer Nature remains neutral with regard to jurisdictional claims in published maps and institutional affiliations. 